\title{
The kinetics and mechanism of an aqueous phase isoprene reaction with hydroxyl radical
}

\author{
D. Huang, X. Zhang, Z. M. Chen, Y. Zhao, and X. L. Shen \\ State Key Laboratory of Environmental Simulation and Pollution Control, College of Environmental Sciences and \\ Engineering, Peking University, Beijing 100871, China
}

Received: 9 March 2011 - Published in Atmos. Chem. Phys. Discuss.: 11 March 2011

Revised: 24 June 2011 - Accepted: 23 July 2011 - Published: 1 August 2011

\begin{abstract}
Aqueous phase chemical processes of organic compounds in the atmosphere have received increasing attention, partly due to their potential contribution to the formation of secondary organic aerosol (SOA). Here, we analyzed the aqueous $\mathrm{OH}$-initiated oxidation of isoprene and its reaction products including carbonyl compounds and organic acids, regarding the acidity and temperature as incloudy conditions. We also performed a laboratory simulation to improve our understanding of the kinetics and mechanisms for the products of aqueous isoprene oxidation that are significant precursors of SOA; these included methacrolein (MACR), methyl vinyl ketone (MVK), methyl glyoxal (MG), and glyoxal (GL). We used a novel chemical titration method to monitor the concentration of isoprene in the aqueous phase. We used a box model to interpret the mechanistic differences between aqueous and gas phase $\mathrm{OH}$ radical-initiated isoprene oxidations. Our results were the first demonstration of the rate constant for the reaction between isoprene and $\mathrm{OH}$ radical in water, 1.2 $( \pm 0.4) \times 10^{10} \mathrm{M}^{-1} \mathrm{~s}^{-1}$ at $283 \mathrm{~K}$. Molar yields were determined based on consumed isoprene. Of note, the ratio of the yields of MVK $(24.1 \pm 0.8 \%)$ to MACR $(10.9 \pm 1.1 \%)$ in the aqueous phase isoprene oxidation was approximately double that observed for the corresponding gas phase reaction. We hypothesized that this might be explained by a waterinduced enhancement in the self-reaction of a hydroxy isoprene peroxyl radical $\left(\mathrm{HOCH}_{2} \mathrm{C}\left(\mathrm{CH}_{3}\right)\left(\mathrm{O}_{2}\right) \mathrm{CH}=\mathrm{CH}_{2}\right)$ produced in the aqueous reaction. The observed yields for MG and GL were $11.4 \pm 0.3 \%$ and $3.8 \pm 0.1 \%$, respectively. Model simulations indicated that several potential pathways may contribute to the formation of MG and GL. Finally, oxalic acid increased steadily throughout the course of the study, even after isoprene was consumed completely. The
\end{abstract}

Correspondence to: Z. M. Chen (zmchen@pku.edu.cn) observed yield of oxalic acid was $26.2 \pm 0.8 \%$ at $6 \mathrm{~h}$. The observed carbon balance accounted for $\sim 50 \%$ of the consumed isoprene. The presence of high-molecular-weight compounds may have accounted for a large portion of the missing carbons, but they were not quantified in this study. In summary, our work has provided experimental evidence that the availably abundant water could affect the distribution of oxygenated organic compounds produced in the oxidation of volatile organic compounds.

\section{Introduction}

Since the 1980s, scientific attention has focused on chemical processes of organic compounds found in the atmospheric aqueous phase, including clouds, fog, rain, and wet aerosols. A considerable number of field and laboratory studies have investigated these processes (e.g., Chameides and Davis, 1982; Gill et al., 1983; Jacob, 1986; Crahan et al., 2004; Yu et al., 2005; Carlton et al., 2006; Legrand and Puxbaum, 2007; Altieri et al., 2008; Liu et al., 2009; Enami et al., 2009, 2010; Zhang et al., 2010). Several specific aqueous phase chemical models (e.g., Jacob, 1986; Lelieveld and Crutzen, 1991; Walcek et al., 1997) and aqueous phase mechanisms (Ervens et al., 2003; Herrmann et al., 2005) were established to understand the aqueous phase chemical processes and to explore the impact of these processes on atmospheric chemistry. Over the past decade, the aqueous phase processes of some organic compounds have been recognized as potentially significant sources of secondary organic aerosol (SOA) (Hallquist et al., 2009). However, previous studies mainly focused on highly-soluble oxygenated volatile organic compounds (OVOCs), including methanol, pyruvic acid (PA), glyoxal (GL), methyl glyoxal (MG), and glycolaldehyde, and their contribution to SOA (e.g., Monod et al., 2000; Carlton et al., 2006, 2007; Altieri et al., 2008; Perri et al., 2009). Based on the assumption that the reactants

Published by Copernicus Publications on behalf of the European Geosciences Union. 
must enter into aqueous solution before the reactions occur, Henry's law constant has been considered a key parameter in the control of aqueous phase chemical processes for organic compounds. In recent years, however, several studies have investigated aqueous ozonolysis (Chen et al., 2008) and $\mathrm{OH}$-initiated oxidation (El Haddad et al., 2009; Liu et al., 2009; Michaud et al., 2009; Zhang et al., 2010) of several moderately-soluble OVOCs (i.e., methacrolein [MACR] and methyl vinyl ketone $[\mathrm{MVK}])$. Those studies suggested that these reactions could potentially contribute to SOA formation in clouds. Quite recently, several other works investigated the aqueous chemistry of poorly-soluble volatile organic compounds (VOCs), like terpenes, which account for a significant fraction of biogenic VOCs (Zhang et al., 2009; Enami et al., 2010). Those studies aimed to find a new pathway for the transformation of VOCs into SOA.

One can say that the Henry's law constants of the poorlysoluble VOCs are so small that their aqueous processes are not of atmospheric relevance. However, the aqueous phase reactions can occur both in bulk water and on the surface of droplets. Considering the large global abundance of reactive poorly-soluble VOCs and the large collective surface of liquid droplets in the atmosphere, it may be important to study the chemical processes of VOCs on the surface of droplets. On one hand, a reactive sink in the aqueous solution for VOCs may active for the phase transfer. Finlayson-Pitts and Pitts described in their book (Finlayson-Pitts and Pitts, 2000) that "Henry's Law can be applied to predict solution concentrations only if certain conditions are met. Thus it assumes that there are no irreversible chemical reactions that are so fast that the equilibrium cannot be established." In other words, if the kinetic rate is fast enough, the thermal dynamic gas-liquid equilibrium would not be achieved, resulting in a much larger amount of the reactant into the aqueous phase from the gas phase. Seinfeld and Pandis (2006) pointed out that "Remarkably few gases fall into the very soluble category. This does not imply, however, that only very soluble gases are important in atmospheric aqueous-phase chemistry." In a very recent work, Enami et al. (2010) reported the fast reaction of terpene with ozone on aqueous surfaces and observed carboxylic acids in $<10 \mu$ s once the gas phase ozone collisions with the surface of aqueous terpene solutions happened, indicating a potential SOA contribution pathway for the aqueous oxidation of poorly-soluble organic compounds. Moreover, Yu et al. (2008) reported that the average residence time of $\alpha$-pinene adsorbing onto the aqueous interface was more than $0.1 \mathrm{~ns}$ in their study of nitrate ion photochemistry oxidation of $\alpha$-pinene at the aqueous interface, and within $1 \mathrm{~ns} \alpha$-pinene resided near the interface, thus the time was enough for the reaction of $\alpha$-pinene and the $\mathrm{OH}$ radical produced by the nitrate photolysis. On the other hand, some research groups studied the aqueous surface/interface adsorption of poorly-soluble gases and found a much higher interface concentration compared to the gas phase concentration. For example, Vácha et al. (2004) calculated the free energy profiles associated with moving atmospheric gases or radicals $\left(\mathrm{N}_{2}, \mathrm{O}_{2}, \mathrm{O}_{3}, \mathrm{OH}, \mathrm{H}_{2} \mathrm{O}, \mathrm{HO}_{2}\right.$, and $\left.\mathrm{H}_{2} \mathrm{O}_{2}\right)$ across the air/water interface, and then they estimated the concentrations of these species in the gas phase, aqueous interface, and aqueous bulk. Their result showed that the average aqueous interface concentration $\left(C_{\text {aqi }}\right)$ was much higher than the corresponding gas phase concentration $\left(C_{\mathrm{g}}\right)$ and aqueous bulk concentration $\left(C_{\mathrm{aqb}}\right)$. For example, the ratios of $C_{\mathrm{aqi}} / C_{\mathrm{g}}$ are 3.62 for $\mathrm{O}_{3}, 8800$ for $\mathrm{OH}$ radical, and $2.6 \times 10^{7}$ for $\mathrm{H}_{2} \mathrm{O}_{2}$, the ratios of $C_{\mathrm{aqi}} / C_{\mathrm{aqb}}$ are 11 for $\mathrm{O}_{3}, 8$ for $\mathrm{OH}$ radical, and 1.5 for $\mathrm{H}_{2} \mathrm{O}_{2}$. Interestingly, the ratio of $C_{\text {aqi }} / C_{\text {aqb }}$ (11) for the poorly-soluble $\mathrm{O}_{3}$ is much higher than that (1.5) of the soluble $\mathrm{H}_{2} \mathrm{O}_{2}$. It is likely that the aqueous interface concentration of hydrophobic gas would be much higher than the calculated concentrations based on the Henry's law constant. So, we expect that poorly-soluble VOCs would undergo a similar fate as $\mathrm{O}_{3}$ does, namely, the interface concentration of VOCs may be much higher than its gas phase and aqueous bulk concentrations. If combining the interface concentrations of reactive sink such as $\mathrm{OH}$ radical and VOCs, it is expected that the interface reaction of poorly-soluble VOCs with $\mathrm{OH}$ would be of importance based on the assumption that the interface rate constant for the reaction of VOCs and $\mathrm{OH}$ is comparative or even higher than that in the gas phase. In summary, all the studies mentioned above indicate that the relative importance of aqueous reaction of a compound is not determined completely by its Henry's law constant. In an overview, Kolb et al. (2010) indicated that the surface activity, concentration, and impact of adsorbed compounds by aqueous particles need further studies. Consequently, we suggest that the aqueous oxidation might be a potential sink of poorly-soluble VOCs in cloud/fog/wet aerosol, or inversely, the aqueous VOCs oxidation would modify (age) the aerosols, although currently we have not quantified this sink or modification yet. Obviously, the cloud/fog/wet aerosol environment provides a huge amount of water molecules in forms of droplet, cluster and adsorbate, and these water molecules will significantly affect the product yields and distribution of VOC oxidation.

In fact, a number of studies investigated the ozonolysis of alkenes and isoprene under high relative humidity conditions (e.g., Neeb et al., 1997; Sauer et al., 1999) and in water (Gäb et al., 1995); those studies revealed that the production of peroxides and carbonyls significantly increased in the presence of water. In addition, it has been suggested that the effects of water on SOA formation would be reversed with the ozonolysis of different substances (Na et al., 2006; Warren et al., 2009). Also, the photochemical reactions of several VOCs, including isoprene (Böge et al., 2006) and aromatics (Kroll et al., 2007; Ng et al., 2007), in the presence of wet seed particles in the chamber were investigated for SOA formation. However, those works did not distinguish the aqueous phase chemical processes from those of the gas phase; nevertheless, they observed that the wet aerosols facilitated the degradation of the poorly-soluble VOCs. 
Currently, little information is available on the aqueous phase chemical processes of poorly-soluble VOCs. The rate constants and mechanism for the aqueous oxidation of VOCs are so limited that one cannot evaluate the relative importance of those aqueous processes. More studies are needed to increase our understanding of the roles of these processes in atmospheric chemistry. In the present work, we would like to study the aqueous phase $\mathrm{OH}$ radical initiated oxidation of isoprene, determine the rate constant and the product distribution and yield, investigate the reaction mechanism in the aqueous phase, and examine how water affects the $\mathrm{OH}$ oxidation of isoprene compared with corresponding gas phase reaction. As mentioned above, the aqueous phase reactions can occur both in bulk and on the surface of water droplets. For isoprene, it would be better to study its surface oxidation on water droplets. However, there is a great challenge for investigating this surface reaction. This challenge arises from the interference of the gas phase reaction. It is a difficult task for one to exclude the gas phase reaction during performing the surface reaction of isoprene because of its high volatility and reactivity and to prevent the gas phase products entering into the aqueous phase, resulting in large uncertainties in determination of the product yield and distribution. In addition, there are great uncertainties for the evaluation of the surface area of droplets, and it is now difficult for us to simultaneously get the size distribution of droplets and to collect the droplets for quantitative analysis. These problems may significantly affect the estimation of the availably abundant water effect on the oxidation of isoprene. Therefore, in the first place, we intend to investigate the aqueous bulk oxidation of isoprene to identify the availably abundant water effect on the product distribution and yields of the isoprene oxidation, and to quantitively tell the difference between the gas phase and aqueous phase reactions.

In the present study, $\mathrm{OH}$ radical was used to initiate isoprene oxidation within the bulk water solution. The resulting small products, including carbonyls and organic acids, were characterized. This provided evidence for the formation of high-molecular-weight compounds (HMWs). In addition, a box model was used to simulate the isoprene-OH radical reaction in the aqueous phase. We intensively investigated the rate constant of the aqueous isoprene-OH reaction and the mechanisms for the production of MACR, MVK, MG, and GL, because they are the major first- and/or second-generation products of isoprene, and they are significant precursors of SOA. Finally, using the determined aqueous rate constant, we evaluate the relative importance of aqueous surface $\mathrm{OH}$ oxidation of isoprene compared with the corresponding gas phase reaction.

\section{Experimental}

\subsection{Reagents and materials}

The solutions were prepared with isoprene (Fluka, 99.5\%); $\mathrm{H}_{2} \mathrm{O}_{2}$ (Acros, 35 wt. \%); and $\mathrm{H}_{2} \mathrm{SO}_{4}$ (Beijing Chemical Plant, $98 \%$ ) diluted in ultrapure water (Milli-pore). The initial concentrations of isoprene and $\mathrm{H}_{2} \mathrm{O}_{2}$ in the reactor were $20 \mu \mathrm{M}$ and $2 \mathrm{mM}$, respectively. This highly-concentrated solution was used to facilitate the characterization of reaction products.

\subsection{Apparatus and procedures}

The aqueous phase photochemical reaction of isoprene and hydrogen peroxide were carried out in a $2.1 \mathrm{~L}$ quartz reactor; details of the apparatus were described previously (Zhang et al., 2010). Briefly, temperature control equipment was placed outside the reactor, and a Xenon arc lamp $\left(300^{\circ} \mathrm{W}\right.$, wavelength: $250 \mathrm{~nm}-380 \mathrm{~nm}$, Perkin Elmer) was placed above the reactor. The arc lamp was the light source for the photolysis of hydrogen peroxide. We sequentially introduced $1400 \mathrm{ml}$ water, $100 \mathrm{ml}$ stock hydrogen peroxide solution, and $500 \mathrm{ml}$ stock isoprene solution into the reactor, for a total volume of $2.0 \mathrm{~L}$. A $0.1 \mathrm{~L}$ gas space was maintained over the liquid level for mixing. A magneton stirred the solution during the entire experiment. The upper limit for the loss of aqueous isoprene was estimated to be $7 \%$, based on the Henry's law constant $\left(0.03 \mathrm{M} \mathrm{atm}^{-1}\right)$ (Sander, 1999). Therefore, gas phase reaction interference was mostly eliminated. Every experiment lasted $6 \mathrm{~h}$. The temperature of the solution in the reactor was maintained at $10 \pm 0.1^{\circ} \mathrm{C}$, and the initial $\mathrm{pH}$ of the solution was either 7.0 or 4.0 .

The gas space was maintained as small as possible, because we found that the gas-liquid exchange affected the variation of the products. In a reaction between isoprene and $\mathrm{H}_{2} \mathrm{O}_{2}$, we compared two different gas spaces with the same initial concentrations. With a gas space of $1.5 \mathrm{~L}$, the amount of products increased steadily during the photolysis process (Fig. S1 in Supplement); with a gas space of $0.1 \mathrm{~L}$, a fluctuating curve was observed, which showed the temporal evolution of the products. This suggested that the gas space should be maintained as small as possible to minimize the disturbance of gas phase reactions on the aqueous chemical process, particularly for species with a small Henry's law constant.

\subsection{Measurement of aqueous phase isoprene}

The aqueous phase isoprene measurement was based on the results from a concurrent study on the aqueous ozonolysis of isoprene (Wang et al., 2011). It was found that aqueous phase isoprene could react with ozone in solution within $5 \mathrm{~min}$ and could produce a series of products, including MACR and MVK. When the ozone was in excess, the MACR and MVK could be further oxidized by ozone, generating MG, PA, 
formaldehyde, and hydroxymethyl hydroperoxide (HMHP), as described previously (Chen et al., 2008). The stoichiometric equation of the final excess ozone reaction revealed a ratio of 1:0.86 of consumed isoprene to formed MG.

With the ozone chemical titration method, based on the ratio of consumed isoprene: formed $\mathrm{MG}$, we measured the concentrations of isoprene solution in the reactor before and during irradiation. The procedure for determining the isoprene concentration was as follows: (1) The $\sim 15 \mu \mathrm{M}$ ozone solution was prepared before the reaction began (Chen et al., 2008); (3) $5 \mathrm{ml}$ isoprene solution was removed from the reactor before and during the irradiation and was rapidly mixed with $45 \mathrm{ml}$ ozone solution in a volumetric flask to ensure a molar ratio of $\sim 5: 1$ of $\mathrm{O}_{3}$ to isoprene; (4) $5 \mathrm{~min}$ later, a $5 \mathrm{ml}$ mixture solution was removed and mixed with $10^{-3} \mathrm{M} 2$,4-dinitrophenylhydrazine (DNPH) solution; (4) after $24 \mathrm{~h}$ of derivation, the mixture was subjected to highperformance liquid chromatography (HPLC) to quantify the carbonyl compounds. For the concentration of isoprene before irradiation, the MG data were used directly to estimate the isoprene concentration, according to the ratio of consumed isoprene to formed MG (1:0.86). However, the sample removed during the irradiation contained residual isoprene in addition to MACR, MVK, and MG formed during the $\mathrm{OH}$-initiated isoprene oxidation. Therefore, the total $\mathrm{MG}\left(\mathrm{MG}_{\mathrm{TOT}}\right)$ produced from ozone chemical titration of the sample comprised the $\mathrm{MG}\left(\mathrm{MG}_{\mathrm{ISO}}\right)$ formed by the ozonolysis of residual isoprene, the MG formed by the ozonolysis of MACR and MVK (MG $\mathrm{MACR}_{\mathrm{MA}}$ and $\mathrm{MG}_{\mathrm{MVK}}$, respectively), and the direct $M G\left(M_{D I R}\right)$. As suggested by Chen et al. (2008), one mole of MACR or MVK was oxidized by ozone into 0.99 or 0.75 mole of MG, respectively. Based on the MG yields mentioned above, we estimated the amount of $\mathrm{MG}_{\text {ISO }}$ with the following equation:

$$
\mathrm{MG}_{\mathrm{ISO}}=\mathrm{MG}_{\mathrm{TOT}}-\mathrm{MG}_{\mathrm{MACR}}-\mathrm{MG}_{\mathrm{MVK}}-\mathrm{MG}_{\mathrm{DIR}}
$$

Then, we could obtain the residual isoprene concentration by combining the $\mathrm{MG}_{\mathrm{ISO}}$ and the ratio (1:0.86) of consumed isoprene to produced $\mathrm{MG}_{\mathrm{ISO}}$.

With the ozone chemical titration method, the average initial concentration of isoprene was estimated to be 21.4 $( \pm 1.7) \mu \mathrm{M}$. This value was similar to the actual value of $20.0 \mu \mathrm{M}$, which was calculated by subtracting the amount of isoprene in the $500 \mathrm{ml}$ stock solution from that distributed in the gas space above the reactor, on the basis of Henry's law at $283 \mathrm{~K}$. This suggested that the ozone titration method provided a reliable tool for determining isoprene concentrations in water solutions.

\subsection{Control experiments}

Several control experiments were conducted to discriminate the different effects of various experimental conditions: isoprene $+\mathrm{UV}$, isoprene $+\mathrm{H}_{2} \mathrm{O}_{2}$, isoprene $+\mathrm{H}_{2} \mathrm{O}_{2}+\mathrm{H}_{2} \mathrm{SO}_{4}+\mathrm{UV}$, mixed standard $+\mathrm{H}_{2} \mathrm{O}_{2}$, and mixed standard+ UV. The mixed standard is composed of the known products containing formaldehyde, GL, MG, formic acid, acetic acid, oxalic acid, and pyruvic acid. The results are as follows: (1) the isoprene decay due to the photolysis is far slower than that by OH-oxidation; (3) $\mathrm{H}_{2} \mathrm{O}_{2}$ cannot obviously result in the transformation of isoprene and carbonyl compounds even at $\mathrm{pH}=4$ in dark; (4) $\mathrm{H}_{2} \mathrm{O}_{2}$ can lead to the transformation of pyruvic acid into acetic acid. However, these subjects are beyond the scope of this study. Our previous work has confirmed that $\mathrm{H}_{2} \mathrm{O}_{2}$ has no significant effect on the transformation of MACR and MVK under the adopted experimental condition (Zhang et al., 2010). We also explored the impact of the aqueous ozone on the derivatization reaction of carbonyls by mixing the reaction products with DNPH instead of ozone under our experimental conditions. The results showed that the influence of ozone on the carbonyl determination was minor $(<8 \%)$.

\subsection{Kinetics experiments}

A competition kinetics method was used to determine the rate constants of $\mathrm{OH}$ oxidation of isoprene, MACR, and MVK. The competitive kinetic experiments were performed in the presence of equal concentrations of isoprene/MACR/MVK and salicylic acid (SA). The concentrations of target compound (TC), i.e., isoprene/MACR/MVK and the reference compound SA were simultaneously monitored during the photolysis and $\ln \left(C_{0} / C_{t}\right)$ for the TC and SA were calculated. Assuming a pseudo first order kinetic for both TC and SA reactions with $\mathrm{OH}$ radical, the slope of $\ln \left([\mathrm{TC}]_{0} /[\mathrm{TC}]_{t}\right)$ versus $\ln \left([\mathrm{SA}]_{0} /[\mathrm{SA}]_{t}\right)$ equals to the ratio of $k_{\mathrm{TC}-\mathrm{OH}} / k_{\mathrm{SA}-\mathrm{OH}}$.

\subsection{Product analysis}

The experimental system used to monitor the products has been described in detail elsewhere (Zhang et al., 2010). Briefly, carbonyl compounds were analyzed by HPLC (Agilent 1100, USA) (Wang et al., 2009), organic acids were analyzed by an ion chromatography (DIONEX 2650, USA) with an ED50 conductivity detector, and high-molecular-weight compounds were analyzed by the HP 1100 LC-MS Trap SL System which included an ion trap mass spectrometer (MS) and an electro-spray interface (ESI).

\subsection{Box model for isoprene- $\mathrm{OH}$ reaction in aqueous phase}

We used a box model for simulating the aqueous $\mathrm{OH}-$ initiated isoprene oxidation. This model was mainly based on the aqueous phase mechanism reported by Herrmann et al. (2005). The specific mechanism implemented in the model for the aqueous MACR/MVK reaction was described previously (Zhang et al., 2010). However, the previous aqueous mechanism did not include the step that enabled isoprene 
to generate MACR and MVK. The gas phase $\mathrm{OH}$-initiated isoprene oxidation production of MACR and MVK in the absence of $\mathrm{NO}_{\mathrm{x}}$ was described by Jenkin et al. (1998) in a series of detailed radical reactions. The main reactions included six hydroxy isoprene peroxyl radicals $\left(R_{\mathrm{hip}} \mathrm{O}_{2}\right)$ that arose from the addition of $\mathrm{OH}$ radical to isoprene (see Scheme 1), their self- and cross-reactions, and subsequent isomerization and decomposition. We included these reactions into the aqueous mechanism of our model. Note that the rate constants of these $R_{\text {hip }} \mathrm{O}_{2}$ reactions required re-estimation, because we used water as the medium.

We determined the integral rate constant $\left(k_{\mathrm{ISO}-\mathrm{OH}, \mathrm{aq}}\right)$ of the aqueous isoprene-OH reaction (see Sect. 3.2), and then assigned the $k_{\mathrm{ISO}-\mathrm{OH} \text {,aq }}$ value to six channels, according to the method described by Jenkin and Hayman (1995). Based on the structure-activity relationship, Jenkin and Hayman suggested that the integral products of the gas phase isoprene-OH reaction were formed by the branching of six hydroxy isoprene peroxyl radicals with specific ratios (Scheme 1), including $15 \%$ for $\mathrm{R} 1 \mathrm{O}_{2}, 45 \%$ for $\mathrm{R}_{2} \mathrm{O}_{2}, 5 \%$ for $\mathrm{R}_{3} \mathrm{O}_{2}, 5 \%$ for $\mathrm{R}_{4} \mathrm{O}_{2}, 8 \%$ for $\mathrm{R}^{2} \mathrm{O}_{2}$, and $22 \%$ for $\mathrm{R}_{6} \mathrm{O}_{2}$. Considering the suggestion that the solvent effect was virtually identical for both reactants and products (Gligorovski and Herrmann, 2004; Monod et al., 2005), we assumed that these six ratios would not change in the aqueous phase.

For the subsequent $R_{\text {hip }} \mathrm{O}_{2}$ reactions, there were no experimental values for the aqueous rate constants. However, Neta et al. (1990) reported the rate constants for a series of peroxyl radicals in aqueous solution. Thus, we selected a number of those peroxyl radicals that had structures similar to the hydroxy isoprene peroxyl radicals. The rate constants for the selected radicals were in the range of $10^{7}-10^{8} \mathrm{M}^{-1} \mathrm{~s}^{-1}$ in water; this was nearly four orders of magnitude lower than the gas phase parameters (in units of $\mathrm{cm}^{3} \mathrm{~mol}^{-1} \mathrm{~s}^{-1}$ ) related to the $R_{\text {hip }} \mathrm{O}_{2}$ radicals (Jenkin et al., 1998). Several studies have attempted to determine a correlation between kinetic data in gas and aqueous phase reactions in order to predict unknown aqueous kinetics with the known gas phase kinetics (Gligorovski and Herrmann, 2004; Monod et al., 2005). Monod et al. (2005) demonstrated that the aqueous phase rate constants of oxygenated compounds were in linear proportion to the gas phase rate constants on a doublelogarithmic scale. We referred to this relationship between reactions conducted in gas and aqueous phases for our calculated ratio of gas/aqueous phase rate constants of MVK and MACR (Sect. 3.2.1). We also compared our calculations to the rate constants presented in works by Neta et al. (1990) and Jenkin et al. (1998). Based on those analyses, we estimated that the rate constants (in units of $\mathrm{M}^{-1} \mathrm{~s}^{-1}$ ) of aqueous phase oxygenated radical reactions were four orders of magnitude lower than those (in units of $\mathrm{cm}^{3} \mathrm{~mol}^{-1} \mathrm{~s}^{-1}$ ) in the corresponding gas phase reactions. Likewise, the aqueous mechanism used in the present study also included the branching ratios for propagating and terminating channels of the $R_{\text {hip }} \mathrm{O}_{2}$ self- and cross-reactions that were presented in

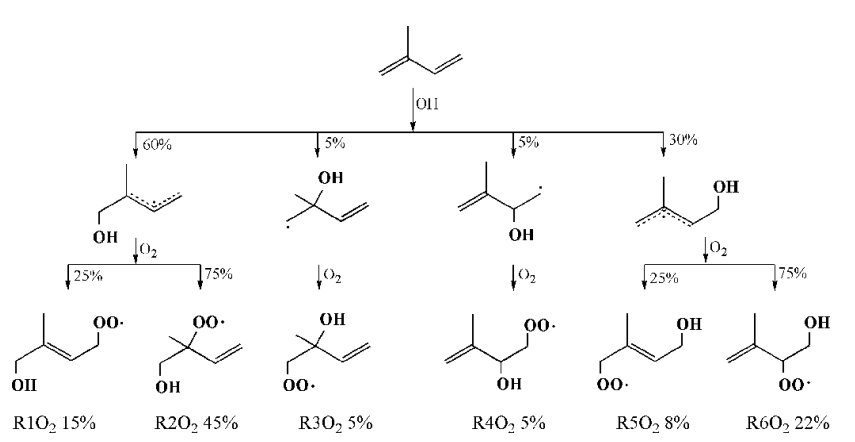

Scheme 1. Mechanisms for the formation of six hydroxy isoprene peroxyl radicals $\left(\mathrm{R} 1 \mathrm{O}_{2}\right.$ through $\left.\mathrm{R} \mathrm{O}_{2}\right)$ and their distributions $(\%)$ from the $\mathrm{OH}$-initiated oxidation of isoprene (top molecule) in the absence of $\mathrm{NO}_{\mathrm{x}}$ (adapted from Jenkin et al., 1998).

the gas phase reactions described by Jenkin et al. (1998). Furthermore, we added two more pathways in the aqueous mechanism for producing MG and GL, which are referred to in two other gas phase models; i.e., the Mainz Isoprene Mechanism 2 (MIM2) (Taraborrelli et al., 2009) and the isoprene photooxidation mechanism described in the Regional Acid Deposition Model 2 (RADM2) (Zimmermann and Poppe, 1996). The rate constants of the peroxyl radical reactions were derived from the aqueous data of Neta et al. (1990) and Jenkin et al. (1998). The detailed mechanism of aqueous $\mathrm{OH}$-initiated isoprene oxidation in the model is shown in Table S1 (Supplement). Here, we mainly focused on the chemical processes of isoprene, MACR, MVK, MG, and GL in the aqueous phase.

\section{Results and discussion}

\subsection{Product analysis}

\subsubsection{Carbonyl compounds}

A series of small molecular weight products were detected in the aqueous $\mathrm{OH}$-initiated oxidation of isoprene. Among these products, we focused on the multifunctional carbonyl compounds, because they were considered to be the precursors of SOA. Figure 1a shows the temporal profiles of MACR, MVK, formaldehyde, acetaldehyde, GL, and MG. The isoprene concentration decreased gradually and was completely consumed within $100 \mathrm{~min}$; in contrast, MACR and MVK, the two first-generation products, increased initially, reached maximum at 20-30 min, and then decreased gradually. Figure 2 shows the linear relation between the MACR/MVK formed and the isoprene consumed; the slopes indicated that the molar yields of MACR and MVK were $17.4 \pm 0.8 \%$ and $7.7 \pm 1.1 \%$, respectively. Here, the molar yield was defined as the ratio of the molar amount of product to the molar amount of consumed isoprene. However, these two yields did not include the MACR/MVK loss 
due to subsequent reactions. We estimated this loss with the method suggested by Ruppert and Becker (2000); this suggested that the actual molar yields were $10.9 \pm 1.1 \%$ for MACR and $24.1 \pm 0.8 \%$ for MVK (Fig. 2). Notably, these two yields significantly differed from the corresponding values for the gas phase $\mathrm{OH}$-initiated isoprene oxidation (13\%$38 \%$ for MVK and $15 \%-35 \%$ for MACR under $\mathrm{NO}_{\mathrm{x}}$-free conditions) (Miyoshi et al., 1994; Jenkin et al., 1998; Benkelberg et al., 2000; Ruppert and Becker, 2000; Lee et al., 2005). For comparison, the aqueous phase $\mathrm{OH}$-initiated oxidation of isoprene produced a ratio of $\sim 2: 1$ for MVK to MACR, or double the ratio $(\sim 1: 1)$ observed in the corresponding gas phase reaction. This result indicated that the mechanism appeared to change in the aqueous oxidation of isoprene compared to the corresponding gas phase reaction. This suggested that availably abundant water may play an important role in the aqueous reaction. The detailed mechanism will be discussed in Sect. 3.2.2.

We observed that MG and GL reached a maximum concentration after $80 \mathrm{~min}$ of irradiation; then, $\mathrm{MG}$ remained at a plateau until $180 \mathrm{~min}$, and GL decreased slowly (Fig. 1a). The apparent yields of MG and GL from isoprene within 80 min were estimated to be $11.4 \pm 0.3 \%$ and $3.8 \pm 0.1 \%$. Interestingly, the production of MG was found to correlate well with that of GL within the first $80 \mathrm{~min}$, with a linear correlation coefficient $(r)$ of 0.997 . Thus, the ratio of MG to GL was 2.5 (Fig. 3). This implied that MG and GL may have come from the same source. The possible production mechanism of these two carbonyl compounds was investigated with a box model (Sect. 3.3.2).

\subsubsection{Organic acids}

We also detected organic acids, including formic acid, acetic acid, propionic acid, pyruvic acid, malonic acid, and oxalic acid (Fig. 1b). Formic acid reached a maximum concentration at $80 \mathrm{~min}$ and then decreased gradually; acetic acid increased gradually and then leveled off. The fates for these two organic acids were assumed to be as described in the aqueous phase reaction system reported by Zhang et al. (2010). Oxalic acid, propionic acid, pyruvic acid, and malonic acid increased gradually with time. The observed oxalic acid yield was $26.2 \pm 0.8 \%$ after $6 \mathrm{~h}$ of irradiation; the observed yields of the $\mathrm{C}_{3}$ acids were $<1 \%$. Here, we focused on the source of oxalic acid in the reaction, because it was considered to be an important component of SOA.

It is notable that isoprene, MVK, and MACR decreased gradually to a low level ( $<10 \%$ maximum) within $80 \mathrm{~min}$, and the aldehyde products, MG, GL, and acetaldehyde reached maximum concentrations at $80 \mathrm{~min}$. In contrast, oxalic acid increased steadily, with yields of $0.2 \pm 0.5 \%$ at $10 \mathrm{~min}, 1.1 \pm 0.3 \%$ at $60 \mathrm{~min}, 7.7 \pm 0.2 \%$ at $150 \mathrm{~min}$, and $26.2 \pm 0.8 \%$ at $360 \mathrm{~min}$. Although the conversion of MG and GL can contribute to the formation of oxalic acid (Carlton et al., 2007; Tan et al., 2010), this conversion would
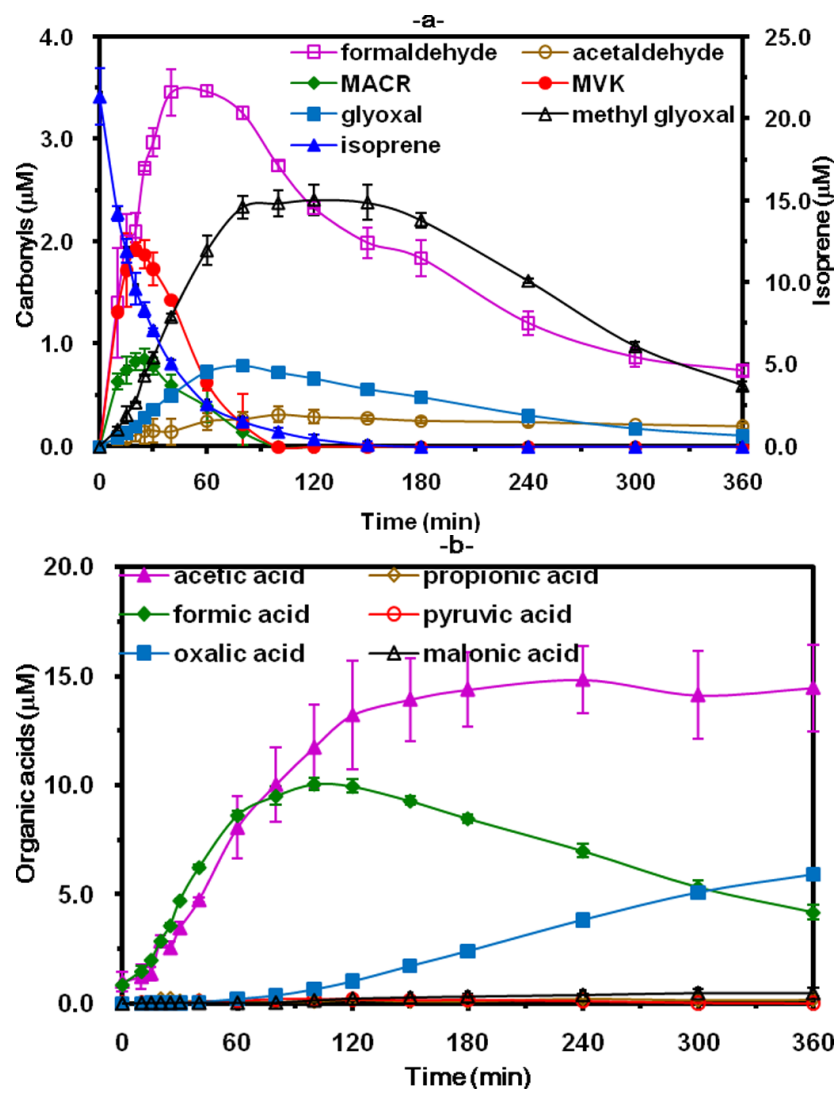

Fig. 1. The major products from the aqueous $\mathrm{OH}$ radical-initiated isoprene oxidation. (a) The time course of the oxidation of isoprene and the concomitant production of carbonyls. (b) The time course for the production of organic acids.

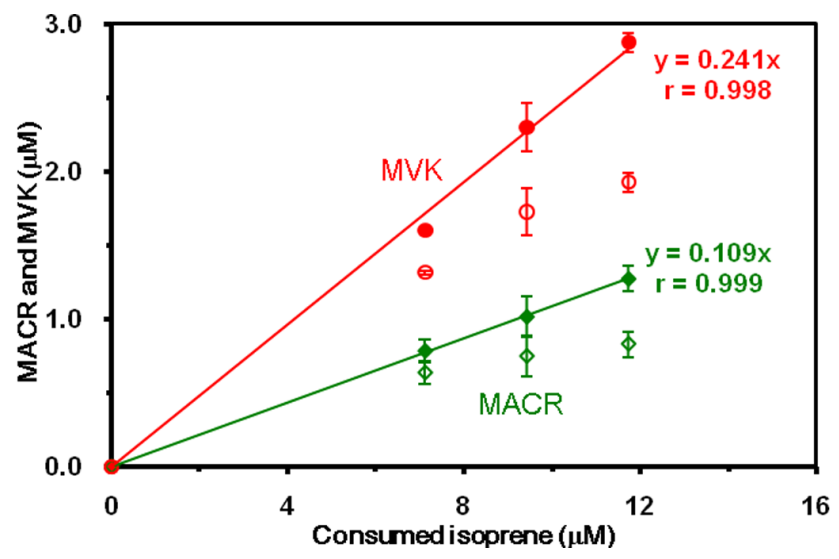

Fig. 2. The amounts of methacrolein (MACR) and methyl vinyl ketone (MVK), formed compared to the isoprene consumed in an aqueous isoprene oxidation. Samples were measured at 10, 15, and $20 \mathrm{~min}$ from the beginning of the reaction. Open symbols are the observed concentrations; solid symbols and fits are the concentrations after correcting for loss due to a reaction with $\mathrm{OH}$, based on the rate constants determined in this work. 


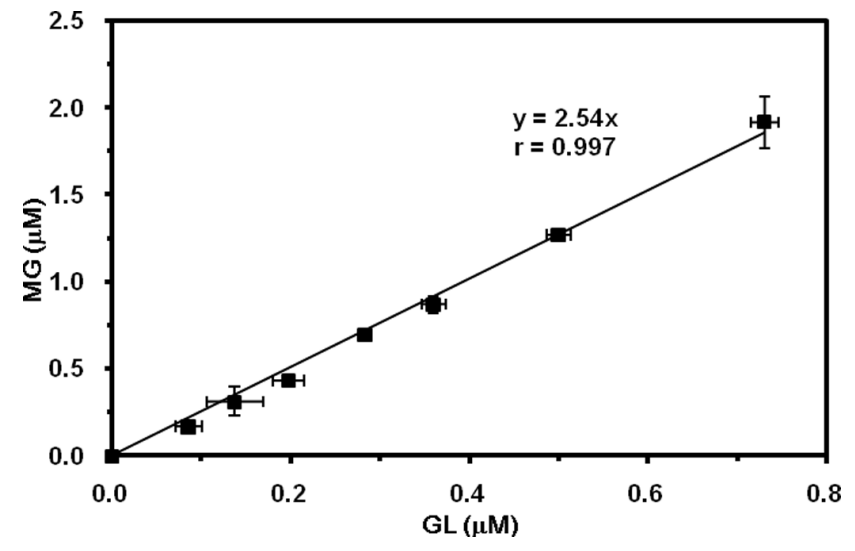

Fig. 3. The relationship between methyl glyoxal (MG) and glyoxal (GL) produced in the aqueous oxidation of isoprene. Samples were measured every $10 \mathrm{~min}$ in the first $80 \mathrm{~min}$ of the reaction.

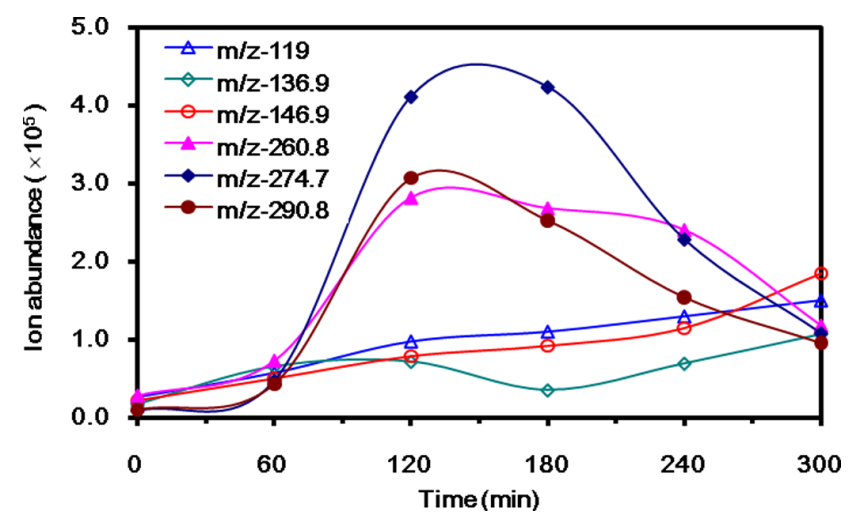

Fig. 4. Detection of the variations in abundance of the ionic molecules produced during the aqueous oxidation of isoprene. $\mathrm{m} / \mathrm{z}$, the mass to charge ratio detected by high-performance liquid chromatography-electrospray ionization-mass spectrometry.

only account for $\sim 50 \%$ of the observed oxalic acid (estimated from the temporal profiles in Fig. 1). The residual portion of oxalic acid might be assigned to the oxidation of undetected aldehydes, including glycolaldehyde and glyoxylic acid (Warneck, 2003), and/or the decomposition of HMWs (Carlton et al., 2007; Zhang et al., 2010).

\subsubsection{High-molecular-weight compounds}

Many studies have shown that low-molecular-weight molecules that contain unsaturated carbon-oxygen double bonds, like MG, GL, glycolaldehyde, MACR, and MVK could react with $\mathrm{OH}$ radical in water to produce highmolecular-weight compounds (HMWs) (Altier et al., 2008; Tan et al., 2009; Perri et al., 2009; Zhang et al., 2010). We found a regular pattern of mass differences $(12,14$, and $16 \mathrm{amu}$ ) among the ions; in related studies, this has been taken as a sign of the formation of oligomers. In the present work, MACR, MVK, GL, MG, and some organic acids were identified as the products of the aqueous isoprene-OH reaction. Thus, the formation of HMWs was expected. In aldehyde-OH studies, HMWs were found to form by esterification of a parent organic acid with several units of multifunctional carbonyls (Tan et al., 2009; Perri et al., 2009). In this study, the negative mode of HPLC-ESI-MS detected two series of ions with mass differences of 12,14 , and $16 \mathrm{amu}$ in the $m / z$ range of 30-300. The abundance of several detected product ions varied with the reaction time (Fig. 4). Ions were also detected in the positive mode of HPLC-ESI-MS, but the ion abundance was lower than the products detected in the negative mode. The acids and aldehydes could be detected as $[\mathrm{M}-\mathrm{H}]{ }^{-}$and $[\mathrm{M}+\mathrm{H}]^{+}$, respectively.

We also noticed three low-molecular-weight products that may have been the parent molecules; these products, $\mathrm{m} / \mathrm{z}^{-} 73.0, \mathrm{~m} / \mathrm{z}^{-} 85.2$, and $\mathrm{m} / \mathrm{z}^{+} 60.8$, were deduced to be glyoxylic acid, methacrylic acid, and glycolaldehyde, respectively. The $m / z^{-} 73.0$ product was identified as glyoxylic acid based on previous studies that showed that a series of products were produced from additions of several $\mathrm{C}_{3} \mathrm{H}_{4} \mathrm{O}_{2}$ (molecular weight $=72.0$ ) to glyoxylic acid (Altieri et al., 2006; Tan et al., 2009; Perri et al., 2009). The $m / z^{-85.2}$ was assumed to be the $\mathrm{m} / \mathrm{z}, 87$ isomeric compound previously detected by proton-transfer reaction mass spectrometry (PTR-MS; Zhao et al., 2004). They identified the $\mathrm{m} / \mathrm{z} 87$ compound as $\mathrm{C}_{4}$-hydroxycarbonyl. With HPLCESI-MS analysis, we deduced that the $\mathrm{m} / \mathrm{z}^{-} 85.2$ signal detected under negative mode was methacrylic acid $\left(\mathrm{C}_{4} \mathrm{H}_{6} \mathrm{O}_{2}\right.$, molecule weight $=86$ ), according to the molecular weight and the assumption that it contained a carboxyl group. Edney et al. (2005) reported the formation of 2-methylglyceric acid in isoprene oxidation products. We suggest that 2methylglyceric acid could transform into methacrylic acid by removing a $\mathrm{H}_{2} \mathrm{O}_{2}$; thus, methacrylic acid produced from the oxidation of MACR could be further oxidized by an $\mathrm{OH}$ radical to generate 2-methylglyceric acid. A similar mechanism was also suggested in isoprene ozonolysis (Sauer et al., 1999). Although the ion abundance of the products detected under the positive mode of ESI-MS was one order of magnitude lower compared with the signal intensity of the products detected under negative mode, we were able to observe a series of products with mass differences of 12,14 , and $16 \mathrm{amu}$. The smallest ion observed in positive mode was $m / z^{+} 60.8$. It was deduced to be glycolaldehyde because it contained a highly electronegative oxygen atom that could attract hydrogen ion; thus, the $[\mathrm{M}+\mathrm{H}]^{+}$could be detected under positive mode. Generally, the ion abundance of the lager molecules $\left(\mathrm{m} / \mathrm{z}>^{-} 250\right)$ was higher than those of smaller molecules $\left(\mathrm{m} / \mathrm{z}<{ }^{-} 150\right)$. The ion abundance of the larger molecules reached maximum between about $100 \mathrm{~min}$ and $150 \mathrm{~min}$, and the ion abundance of the smaller molecules continued to grow throughout the experiment. The larger molecule profiles tended to be similar to aldehyde profiles, except the peak time was delayed. The sustained growing 
abundance of smaller products may be attributed to the decomposition of the larger HMWs. Unfortunately, we were unable to identify and quantify the HMWs, because the standards are unavailable.

\subsection{4 pH effects on products}

The effect of acidity on the reaction was also investigated by comparing the reaction in solutions with two different initial $\mathrm{pH}$ values of 7.0 or 4.0. The results showed no obvious differences between $\mathrm{pH} 4.0$ and $\mathrm{pH} 7.0$ in the yields of organic acids and carbonyls formed in the aqueous $\mathrm{OH}$-initiated isoprene oxidation. This suggested that acidity had a negligible effect on the formation of the identified products. However, it has been shown that high acidity ( $\mathrm{pH}$ 4.0) could affect the HPLC-ESI-MS determination of HMWs, because the ionization of HMWs appears to be restricted in an acidic solution. This would result in a low sensitivity of HPLC-ESI-MS for the detection of HMWs under the negative mode.

\subsubsection{Carbon balance}

On the basis of the observed products, we estimated the carbon balance (ratio of observed carbon versus consumed carbon) of the investigated reaction system as a function of time (Fig. 5). The observed carbon balance was expected to account for $\sim 50 \%$ of the consumed isoprene. The missing carbons most likely included carbon dioxide, organic peroxides, hydroxyl-containing compounds, and HMWs. HMWs may account for a large portion of the missing carbons. Unfortunately, we have not quantified the HMWs, because there are no standards available. However, our analysis of the observed products could characterize, to some extent, the aqueous $\mathrm{OH}$-initiated isoprene oxidation.

\subsection{Mechanism and modeling}

\subsubsection{The kinetics of isoprene, MACR, and MVK}

The ratios of $k_{\mathrm{ISO}-\mathrm{OH}} / k_{\mathrm{SA}-\mathrm{OH}}, k_{\mathrm{MACR}-\mathrm{OH}} / k_{\mathrm{SA}-\mathrm{OH}}$, and $k_{\mathrm{MVK}-\mathrm{OH}} / k_{\mathrm{SA}-\mathrm{OH}}$ are $0.75( \pm 0.25), 0.78( \pm 0.12)$, and 0.76 $( \pm 0.06)$ respectively (Fig. S2 in the Supplement). Buxton et al. (1988) suggested a rate constant of SA react with $\mathrm{OH}$ radical, that is $k_{\mathrm{SA}-\mathrm{OH}}=2.2 \times 10^{10} \mathrm{M}^{-1} \mathrm{~s}^{-1}$ at room temperature $(\sim 298 \mathrm{~K})$. The activation energy $\left(E_{\mathrm{a}}\right)$ of SA$\mathrm{OH}$ radical reaction is unavailable; thus, we estimated its value with $\sim 15 \mathrm{~kJ} \mathrm{~mol}^{-1}$ by combining the $E_{\mathrm{a}}$ values of the $\mathrm{OH}$ radical reaction with unsaturated oxygenated compounds and ones of the $\mathrm{NO}_{3}$ radical reaction with aromatic compounds (Herrmann et al., 2010). Based on this $E_{\mathrm{a}}$ value, we estimated $k_{\mathrm{SA}-\mathrm{OH}}=1.6 \times 10^{10} \mathrm{M}^{-1} \mathrm{~s}^{-1}$ at $283 \mathrm{~K}$. Consequently, we estimated the aqueous phase $\mathrm{OH}-$ oxidation rate constants were $1.2( \pm 0.4) \times 10^{10} \mathrm{M}^{-1} \mathrm{~s}^{-1}$ for isoprene, $1.3( \pm 0.2) \times 10^{10} \mathrm{M}^{-1} \mathrm{~s}^{-1}$ for MACR, and $1.2( \pm 0.1) \times 10^{10} \mathrm{M}^{-1} \mathrm{~s}^{-1}$ for MVK. Our determined $k_{\mathrm{MACR}-\mathrm{OH}}$ agree well with that recently reported by Glig-

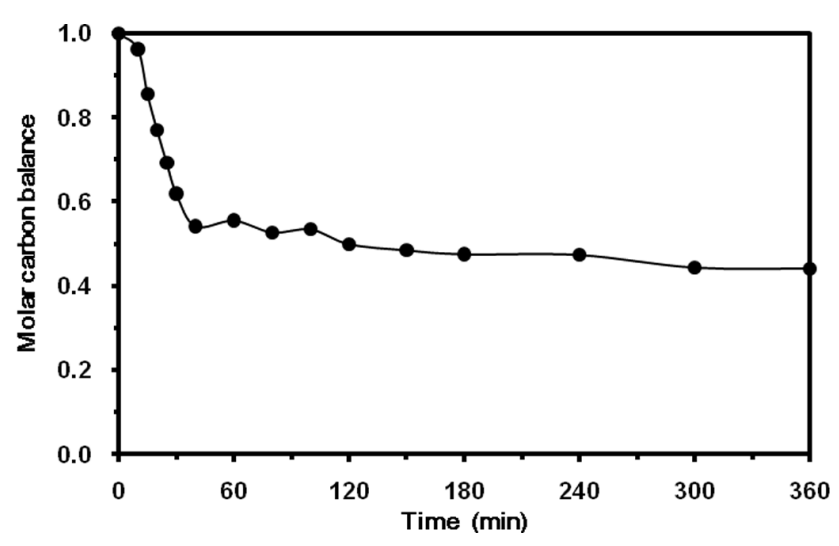

Fig. 5. The observed carbon balance (ratio of observed carbon versus consumed carbon) as a function of time during the aqueous oxidation of isoprene. Total experimental time was $6 \mathrm{~h}$.

orovski et al. (2009), that is, $9.2 \times 10^{9} \mathrm{M}^{-1} \mathrm{~s}^{-1}$. To our knowledge, this was the first experimentally derived rate constant for aqueous OH-oxidation of isoprene. These three determined rate constants were used in our newly established model. Considering that the corresponding gas phase rate constant $\left(k_{\mathrm{ISO}-\mathrm{OH}, \mathrm{gas}}\right)$ is $6.4 \times 10^{13} \mathrm{~cm}^{3} \mathrm{~mol}^{-1} \mathrm{~s}^{-1}$ at $283 \mathrm{~K}$ (Atkinson et al., 2006), we estimate that the rate constant ratio $\left(R_{\mathrm{k}, \mathrm{ISO}}\right)$ of $k_{\mathrm{ISO}-\mathrm{OH}, \text { aq }}$ to $k_{\mathrm{ISO}-\mathrm{OH}, \mathrm{gas}}$ is about $2 \times 10^{-4}$. For the gas phase rate constants for MACR $\left(k_{\mathrm{MACR}-\mathrm{OH}, \mathrm{gas}}\right)$ and $\operatorname{MVK}\left(k_{\mathrm{MVK}-\mathrm{OH}, \mathrm{gas}}\right)$ are $1.8 \times 10^{13} \mathrm{~cm}^{3} \mathrm{~mol}^{-1} \mathrm{~s}^{-1}$ and $1.3 \times 10^{13} \mathrm{~cm}^{3} \mathrm{~mol}^{-1} \mathrm{~s}^{-1}$, respectively, at $283 \mathrm{~K}$ (Atkinson et al., 2006). Thus, the aqueous to gas rate constant ratios at $283 \mathrm{~K}$ are estimated to be $R_{k, \mathrm{MACR}}=7 \times 10^{-4}$ for MACR and $R_{k, \mathrm{MVK}}=9 \times 10^{-4}$ for MVK.

\subsubsection{Mechanism and model simulation}

A plausible mechanism for the aqueous $\mathrm{OH}$-initiated isoprene oxidation was simulated with a box model to facilitate our understanding of the aqueous phase processes. Conversely, by comparing the model results to our experimental data, we could find deficiencies in the newly conceived mechanism described in Sect. 2.7, and then we could modify the mechanism based on reasonable explanations.

\section{Explaining the ratio of MVK to MACR}

First, we ran the model with the initial kinetic parameters described in Sect. 2.7 and Table S1 (Supplement). We found that the model reproduced the experimentally observed profile of isoprene in the reaction, but poorly predicted the observed profiles of MACR and MVK production (Fig. 6a). The predicted yield of MVK $(10.1 \%)$ was much lower than the observed yield (17\%), and the predicted yield of MACR $(13.0 \%)$ was much higher than the observed yield $(6.5 \%)$. The predicted yield ratio $(\sim 1)$ of MVK to MACR was half that observed $(\sim 2)$ in the aqueous phase $\mathrm{OH}$-initiated 

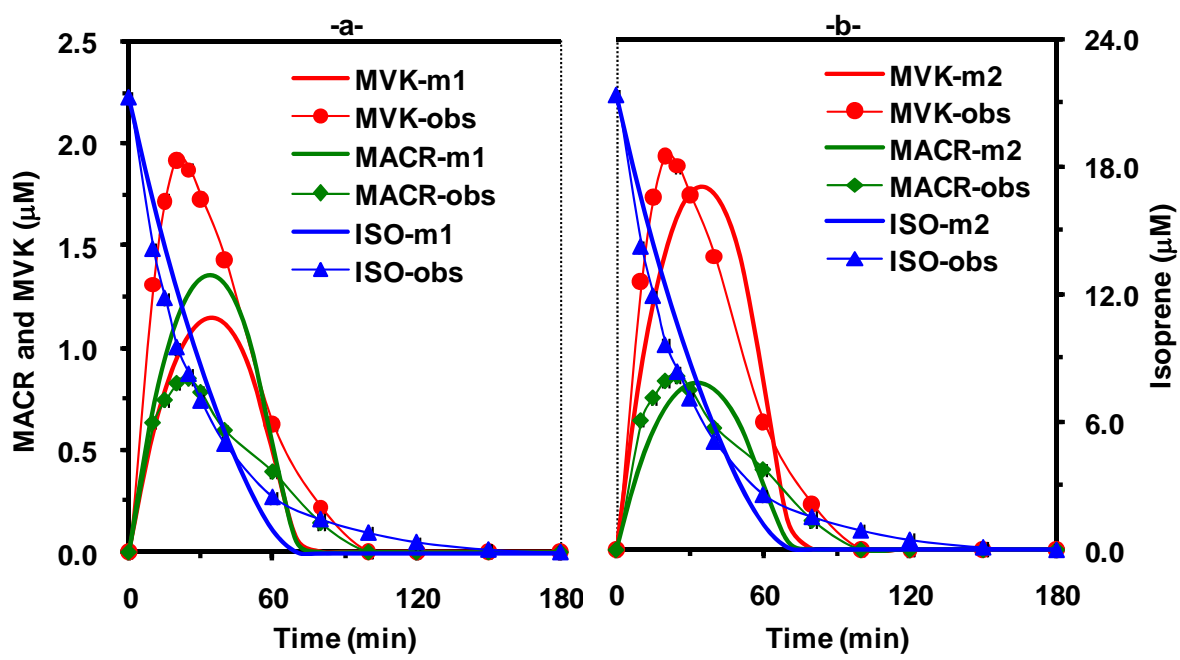

Fig. 6. Model-measurement comparison for isoprene, methyl vinyl ketone (MVK), and methacrolein (MACR) abundances during the aqueous oxidation of isoprene. (a) The model simulation was performed with the initial kinetic parameters (m1). (b) The model simulation was performed with the adjusted kinetic parameters (m2). obs, observed profiles.

isoprene oxidation, but close to that observed $(\sim 1)$ in the corresponding gas phase reaction (Jenkin et al., 1998). This implied that the channel ratio for forming MVK and MACR might be significantly modified by water. This modification may arise from a change in the rate constants for $R_{\text {hip }} \mathrm{O}_{2}$ reactions.

In the initial kinetic parameters of the present model, note that the rate constants for all six of the $R_{\text {hip }} \mathrm{O}_{2}$ radical self reactions were assumed to be proportional to those of the corresponding gas phase reactions; but, the value for the $\mathrm{R}_{2} \mathrm{O}_{2}$ radical was two orders of magnitude lower than those of the other five radicals. Jenkin and Hayman (1995) suggested that the $\mathrm{R}_{2} \mathrm{O}_{2}$ is a tertiary radical and not as active as the other five $R_{\text {hip }} \mathrm{O}_{2}$ radicals in the gas phase. However, it is unknown whether this remains to be true in the aqueous phase. Several studies have demonstrated that, in the presence of water, the peroxyl radicals $\left(\mathrm{HO}_{2}\right.$ and $\left.\mathrm{RO}_{2}\right)$ can bind with water to form $\mathrm{HO}_{2} \cdot \mathrm{H}_{2} \mathrm{O}$ (Aloisio and Francisco, 1998; Reichert et al., 2003; Suma et al., 2006) or $\mathrm{RO}_{2} \cdot \mathrm{H}_{2} \mathrm{O}$ (English et al., 2008). The $\mathrm{HO}_{2} \cdot \mathrm{H}_{2} \mathrm{O}$ complex has been observed in the laboratory (Suma et al., 2006). Furthermore, the kinetics and product branching distributions could be affected by complex formation; this effect has been found in the $\mathrm{HO}_{2}-\mathrm{H}_{2} \mathrm{O}$ (Reichert et al., 2003) and $\mathrm{HO}_{2}-\mathrm{NO}-\mathrm{H}_{2} \mathrm{O}$ reaction systems (Butkovskaya et al., 2005). Although the $\mathrm{RO}_{2} \cdot \mathrm{H}_{2} \mathrm{O}$ complexes have not been observed directly, there is computational evidence for their existence (Clark et al., 2008). Because the present reaction system used water as the medium, the formation of the $\mathrm{RO}_{2} \cdot \mathrm{H}_{2} \mathrm{O}$ complex might be expected. Recently, Clark et al. (2010) showed a computational result for the formation probability of fresh isoprene $R_{\text {hip }} \mathrm{O}_{2} \cdot \mathrm{H}_{2} \mathrm{O}$ complexes in the gas phase at $100 \%$ relative humidity, as follows: $7 \%$ for $\mathrm{R}^{2} \mathrm{O}_{2}, 0.9 \%$ for $\mathrm{R}_{2} \mathrm{O}_{2}, 1.4 \%$ for $\mathrm{R}_{3} \mathrm{O}_{2}, 0.8 \%$ for $\mathrm{R}_{4} \mathrm{O}_{2}, 16.2 \%$ for $\mathrm{R}^{2} \mathrm{O}_{2}$, and $2.5 \%$ for $\mathrm{R}_{6} \mathrm{O}_{2}$. These ratios are expected to increase significantly in condensed water. Among the six $R_{\text {hip }} \mathrm{O}_{2}$ radicals, the $\mathrm{R}_{2} \mathrm{O}_{2}$ radical was the most hydrophobic, because its peroxyl group is surrounded by three alkyl groups. This causes difficulties in forming hydrogen bonds with water molecules. This property may cause the $\mathrm{R}_{2} \mathrm{O}_{2}$ radical to aggregate in water like the insoluble organics (Breslow, 1992). Thus, the $\mathrm{R}^{2} \mathrm{O}_{2}$ radical may have a higher probability of self-collision compared to other $R_{\text {hip }} \mathrm{O}_{2}$ radicals, which can readily combine with water. Therefore, the rate constant of the self-reaction between $\mathrm{R}_{2} \mathrm{O}_{2}$ radicals may increase in water. This increased self-reaction rate would produce more MVK than expected, because the $\mathrm{R}_{2} \mathrm{O}_{2}$ radical is the main precursor for MVK. Conversely, this change would lead to a decrease in MACR production. MACR is produced by the decomposition of the $\mathrm{R} 6 \mathrm{O}$ radical, which is derived from an $\mathrm{R} 6 \mathrm{O}_{2}$ self-reaction and its cross-reaction with other $R_{\mathrm{hip}} \mathrm{O}_{2}$ radicals, particularly $\mathrm{R}_{2} \mathrm{O}_{2}\left(45 \%\right.$ of the all $R_{\text {hip }} \mathrm{O}_{2}$ radicals; see Scheme 1$)$. Clearly, the increase in the $\mathrm{R}_{2} \mathrm{O}_{2}$ self-reaction would decrease the cross-reaction between $\mathrm{R}_{2} \mathrm{O}_{2}$ and $\mathrm{R}_{6} \mathrm{O}_{2}$, which would indirectly result in the observed decrease in MACR.

Based on the above analysis and the initial kinetic parameters, we adjusted the aqueous phase rate constants for the $R_{\text {hip }} \mathrm{O}_{2}$ self- and cross-reactions, based on the observed $\mathrm{MVK}$ and MACR. The rate constant for the $\mathrm{R}_{2} \mathrm{O}_{2}$ self reaction was enhanced to the same order of magnitude as the rate constants for the other $R_{\text {hip }} \mathrm{O}_{2}$ self-reactions (Table $\mathrm{S} 1$ ). The output of this $\mathrm{R}_{2} \mathrm{O}_{2}$-adjusted model is shown in Fig. 6b. The predicted isoprene, MVK, and MACR concentrations agree reasonably well with the observed concentrations. To further validate the hypothesis that the $\mathrm{R}_{2} \mathrm{O}_{2}$ self-reaction would be enhanced by water, we carried out a sensitivity analysis by 
adjusting the rate constants of self- and cross-reactions $\left(k_{\mathrm{s}}\right.$ and $k_{\mathrm{c}}$ ) for the six $R_{\text {hip }} \mathrm{O}_{2}$ radicals. The model responses, represented by MVK and MACR concentrations as a function of time, were: (i) When all the $k_{\mathrm{s}}$ and $k_{\mathrm{c}}$ values were simultaneously raised or lowered by two orders of magnitude, the predicted concentrations for MVK and MACR were almost the same as those predicted by the corresponding initial or $\mathrm{R}_{2} \mathrm{O}_{2}$-adjusted model (Fig. 7a and b). Thus, simultaneously changing the rate constants for the self- and crossreactions of the six $R_{\mathrm{hip}} \mathrm{O}_{2}$ radicals did not change the product branching distributions. (ii) When the $k_{\mathrm{s}}$ and $k_{\mathrm{c}}$ for the $\mathrm{R}_{6} \mathrm{O}_{2}$ radical in the initial model were lowered by two orders of magnitude (because the high ratio of MVK/MACR may also be caused by the inhibition of MACR production), the maximum MVK concentration increased by $10.6 \%$, and the maximum MACR concentration decreased by $15.7 \%$ compared to the initial model result (Fig. 7c). However, there was a large discrepancy between the predicted and observed concentrations for MVK and MACR. This result implied that the inhibition of $\mathrm{R} \mathrm{O}_{2}$ reaction was not the dominant factor leading to the high ratio of MVK/MACR, although the inhibition may exist. In summary, we suggest that the $\mathrm{R}^{2} \mathrm{O}_{2}$ radical was the most sensitive of the six radicals for the production of MVK and MACR; in addition, water may increase its self-reaction probability, which would result in a higher MVK/MACR ratio in the $\mathrm{OH}$-initiated isoprene oxidation compared to the corresponding gas phase reaction. Clearly, further study is needed to determine the actual rate constants for the reactions of $R_{\mathrm{hip}} \mathrm{O}_{2}$ radicals in the aqueous phase.

\section{Explaining the mechanism of MG and GL formation}

In the gas phase, MG and GL are considered to be produced by the oxidation of VOCs like isoprene (Fu et al., 2008). Both MG and GL are highly soluble in water. When they enter into the aqueous phase through gas/aqueous transfer, their oxidation and oligomerization are considered to be important contributors to SOA formation (Volkamer et al., 2007; Tan et al., 2010). Very recently, Schwier et al. (2010) have found that the cross-reactions of glyoxal and methylglyoxal produce a series of aldol and hemiacetal species and will contribute to SOA mass. These two dicarbonyl compounds are considered to be second-generation products of isoprene oxidation, because they are primarily produced from the oxidation of MVK, MACR, and other first-generation carbonyls (Fu et al., 2008). In the present study, we provided experimental evidence that aqueous isoprene oxidation led to the formation of MG and GL. We estimated that, through the intermediate MACR/MVK pathway (P1a), the yield of MG from isoprene was $3.7 \%$. This was derived by considering the yields of MVK/MACR from isoprene $(18.9 \%$ and $9.0 \%$ respectively) and the yields of MG from MVK/MACR $(15.0 \%$ and $10.0 \%$, respectively; Zhang et al., 2010) in the $\mathrm{OH}$-initiated oxidation. Similarly, we estimated that, through the intermediate MVK pathway (P1b), the yield of
GL from isoprene was $0.6 \%$. However, these estimated yields based on P1 were much lower than the observed values $(11.4 \pm 0.3 \%$ for $\mathrm{MG}$ and $3.8 \pm 0.1 \%$ for GL); this implied that a large proportion of the MG and GL production may be derived from other pathways. However, information about the other pathways for the gas phase reaction also remains uncertain; e.g., the mechanism for explaining MG production in MIM2 (P2; Taraborrelli et al., 2009) is different from that used in RADM2 (P3; Zimmermann and Poppe, 1996). The three pathways are as follows:

$$
\begin{aligned}
& \mathrm{MACR} \rightarrow \mathrm{MACRAO}_{2} \rightarrow \mathrm{MG} \\
& \mathrm{MVK} \rightarrow \mathrm{MVKAO}_{2} \rightarrow 0.6 \times \mathrm{MG} \\
& \mathrm{MVK} \rightarrow \mathrm{MVKBO}_{2} \rightarrow 2 \times \mathrm{MVKBA} \rightarrow \mathrm{MG} \\
& \mathrm{MVK} \rightarrow \mathrm{MVKAO}_{2} \rightarrow 1.4 \times \mathrm{GLC} \rightarrow \mathrm{GL}
\end{aligned}
$$

MIM2:

$$
\begin{aligned}
\mathrm{R} 1 O_{2} & \rightarrow \mathrm{C}_{5} \mathrm{H}_{8} \mathrm{O}_{2} \rightarrow 0.52 \times \mathrm{C}_{5} \mathrm{H}_{9} \mathrm{O}_{5} \rightarrow 0.5 \times \mathrm{MG} \\
& +0.5 \times \mathrm{GL} \\
\mathrm{R}_{5} \mathrm{O}_{2} & \rightarrow \mathrm{C}_{5} \mathrm{H}_{8} \mathrm{O}_{2} \rightarrow 0.52 \times \mathrm{C}_{5} \mathrm{H}_{9} \mathrm{O}_{5} \rightarrow 0.5 \times \mathrm{MG} \\
& +0.5 \times \mathrm{GL}
\end{aligned}
$$

\section{RADM2:}

$$
\begin{gathered}
\mathrm{MACRO}_{2}+R_{\mathrm{hip}} \mathrm{O}_{2} \rightarrow 0.3 \times \mathrm{MACR}+0.3 \times \mathrm{MVK} \\
+0.6 \times \mathrm{MG}+\mathrm{HCHO}+1.2 \times \mathrm{HO}_{2}+\mathrm{P} \\
\mathrm{MVKO}_{2}+R_{\mathrm{hip}} \mathrm{O}_{2} \rightarrow 0.3 \times \mathrm{MACR}+0.3 \times \mathrm{MVK} \\
+0.6 \times \mathrm{MG}+\mathrm{HCHO}+1.2 \times \mathrm{HO}_{2}+\mathrm{P}
\end{gathered}
$$

In the P1 pathway, the $\mathrm{MACRAO}_{2}$ represent the addition product of MACR react with $\mathrm{OH}$ radical and $\mathrm{O}_{2}$, that is $\mathrm{CH}_{2}(\mathrm{OH}) \mathrm{C}(\mathrm{OO} \times)\left(\mathrm{CH}_{3}\right) \mathrm{CHO}$; likewise the fate of $\mathrm{MVKAO}_{2}$ and $\mathrm{MVKBO}_{2}$, they represent $\mathrm{CH}_{2}(\mathrm{OH}) \mathrm{C}(\mathrm{OO}$. ) $\mathrm{HC}(\mathrm{O}) \mathrm{CH}_{3}$ and ${ }^{\circ} \mathrm{OOCH}_{2} \mathrm{CH}(\mathrm{OH}) \mathrm{C}(\mathrm{O}) \mathrm{CH}_{3}$ respectively; MVKBA arises from the self collision of $\mathrm{MVKBO}_{2}$ and represents $\mathrm{CH}_{3} \mathrm{C}(\mathrm{O}) \mathrm{C} \cdot \mathrm{H}(\mathrm{OH})$, which could decompose into MG; GLC represents glycolaldehyde. In the P2 reactions, the decomposition of $\mathrm{R} \mathrm{O}_{2} / \mathrm{R} \mathrm{O}_{2}$ leads to the production of the $\mathrm{C}_{5} \mathrm{H}_{8} \mathrm{O}_{2}$ radical, which is carbonyl with internal double bond. Then, the $\mathrm{OH}$ and $\mathrm{O}_{2}$ addition product of $\mathrm{C}_{5} \mathrm{H}_{8} \mathrm{O}_{2}$ radical, that is $\mathrm{C}_{5} \mathrm{H}_{9} \mathrm{O}_{5}$ peroxy radical, is degraded into MG and GL through two channels. In the P3 reactions, $\mathrm{MACRO}_{2} / \mathrm{MVKO}_{2}$ radicals were the products of the addition of $\mathrm{OH}$ and $\mathrm{O}_{2}$ to $\mathrm{MACR} / \mathrm{MVK}$, each represented two isomers; $R_{\text {hip }} \mathrm{O}_{2}$ represents all the hydroxy isoprene peroxyl radicals; the products, $\mathrm{P}$, represent alcohols, peroxides, and other potential products. Note: the specific reactions are listed in Table S1 (Supplement). 

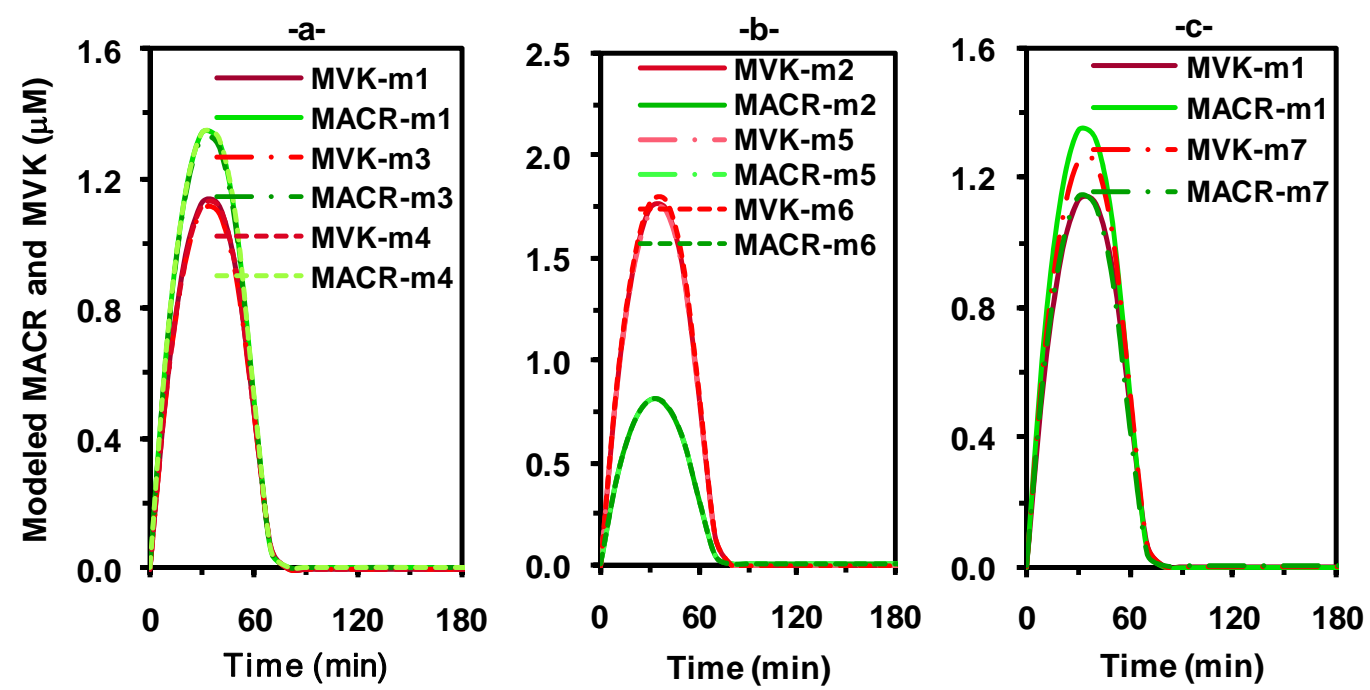

Fig. 7. Comparison of model simulations of the concentration changes in methyl vinyl ketone (MVK) and methacrolein (MACR) during the aqueous oxidation of isoprene. (a) The model rate constants for the self- and cross-reactions (No. 11-51 reactions in Table $\mathrm{S} 1$ ) of six $R_{\text {hip }} \mathrm{O}_{2}$ radicals were raised (or lowered) by two orders of magnitude, based on the initial model parameters (i.e., the same as those in $\mathrm{m} 1$ in Fig. 6 a.). $\mathrm{m} 1$, initial; $\mathrm{m} 3$, lowered; $\mathrm{m} 4$, raised. (b) The model rate constants for the self- and cross-reactions (No. 11-51 reactions in Table S1) of six $R_{\text {hip }} \mathrm{O}_{2}$ radicals were raised (or lowered) by two orders of magnitude, based on the adjusted parameters (i.e., the same as those in $\mathrm{m} 2$ in Fig. 6b). m2, adjusted; m5, lowered; $\mathrm{m} 6$, raised. (c) The model rate constants for $\mathrm{R}^{6} \mathrm{O}_{2}$ self- and cross-reactions were lowered by two orders of magnitude, based on the initial model parameters. m1, initial; m7, lowered.

We tentatively added the $\mathrm{P} 2$ and $\mathrm{P} 3$ pathways to our aqueous reaction model to improve the prediction for the formation of MG and GL. The aqueous phase rate constants for MG and GL were estimated by proportioning the corresponding gas phase rate constants with the method described in Sect. 2.6; the data is shown in Table S1. The results from the model simulation indicated that (i) when neither of P2 or P3 was added to the aqueous model, the predicted amounts of MG and GL were mainly derived from the oxidation of MVK and MACR, and the amounts were much less than the observed values, as mentioned previously; (ii) when P3 was added to the model, the predicted MG and GL increased slightly; (iii) when both P3 and P2 were added to the model, the predicted MG and GL both increased significantly, but the predicted maximum GL concentration was $49 \%$ higher than the observed concentration and the predicted MG was $18 \%$ lower than the observed concentration (Fig. 8). As mentioned in Sect. 3.1.1, the amounts of MG and GL produced were well correlated, suggesting they may have come from the same source. The P2 pathway supported this hypothesis and appeared to be a suitable candidate. As mentioned previously, the production ratio $(0.5: 0.5)$ of MG to GL assumed in the $\mathrm{P} 2$ pathway did not predict the observed result of 0.73:0.27 obtained in our experiment. We applied this observed ratio to the model and found that the modified model could predict the MG and GL concentrations in the first stage of the reaction, when the MG and GL increased gradually, but failed to predict the second stage (an MG plateau) and the third stage (MG and GL declines; Fig. 1). The fact that the model could not reproduce the decay of the isoprene oxidation products is a common problem among box models (Lee et al., 2005; Zhang et al., 2010). This implied that a complex secondary production mechanism might be involved in the production of MG and GL.

The HMWs may also contribute to MG and GL production. Figure 5 shows that most HMWs began to decrease after $100 \mathrm{~min}$, implying the possibility that further degradation of HMWs could contribute to MG and GL formation. Altieri et al. (2008) observed an increase in the abundance of $\mathrm{m} / \mathrm{z} 89$ and a decrease in HMWs after $380 \mathrm{~min}$ in the reaction of MG with $\mathrm{OH}$ radicals. This result may provide a clue for a process in which MG and GL could be produced by HMW degradation, because $m / z, 89$ could possibly represent the hydrated forms of MG and GL. Unfortunately, the information on HMWs presented in the present work was insufficient to quantitatively evaluate their contribution to MG and GL.

\section{Conclusions and implications}

We investigated the $\mathrm{OH}$-initiated oxidation of isoprene in the aqueous phase. This study was the first to determine aqueous phase $\mathrm{OH}$-oxidation rate constant for isoprene, that is $1.2( \pm 0.4) \times 10^{10} \mathrm{M}^{-1} \mathrm{~s}^{-1}$ at $283 \mathrm{~K}$; meanwhile, the rate constants for MACR and MVK were determined as $1.3( \pm 0.2) \times 10^{10} \mathrm{M}^{-1} \mathrm{~s}^{-1}$ for MACR, and 1.2 


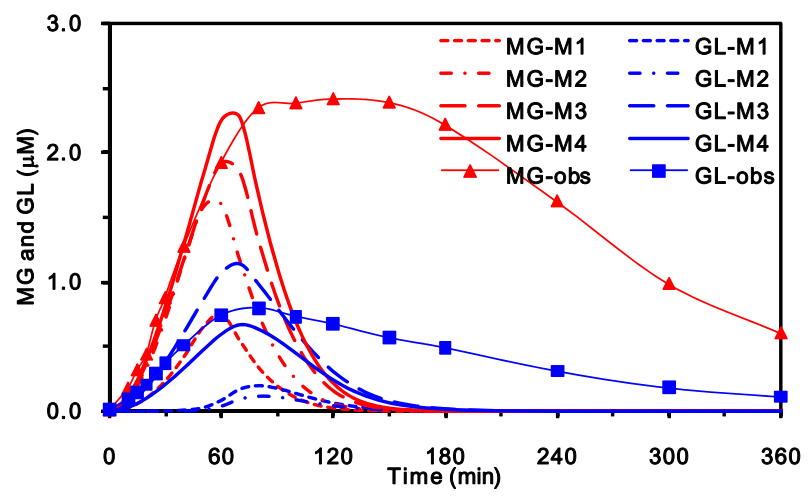

Fig. 8. Model-measurement comparison for methyl glyoxal (MG) and glyoxal (GL) abundances during the aqueous oxidation of isoprene. The model simulations were performed with different MG production pathways. M1, only $\mathrm{P} 1$ pathway; $\mathrm{M} 2, \mathrm{P} 1+\mathrm{P} 3$ pathways; $\mathrm{M} 3, \mathrm{P} 1+\mathrm{P} 2+\mathrm{P} 3$ pathways (in $\mathrm{P} 2$ pathway: $\mathrm{MG}: \mathrm{GL}=0.5: 0.5$ ); $\mathrm{M} 4$, $\mathrm{P} 1+\mathrm{P} 2+\mathrm{P} 3$ pathways (in $\mathrm{P} 2$ pathway: $\mathrm{MG}: \mathrm{GL}=0.73: 0.27$ ). obs, observed profiles.

$( \pm 0.1) \times 10^{10} \mathrm{M}^{-1} \mathrm{~s}^{-1}$ for MVK at $283 \mathrm{~K}$. A series of products, including carbonyl compounds and organic acids were well characterized. We estimated the molar yields $\left(\mathrm{Y}_{i}\right.$, based on the consumed isoprene) of MVK, MACR, MG, GL, and oxalic acid (OA), which are considered to be important contributors to SOA. We found that the $\mathrm{Y}_{\mathrm{MVK}}(18.9 \pm 0.8 \%)$ and $\mathrm{Y}_{\mathrm{MACR}}(9.0 \pm 1.1 \%)$ observed in the aqueous phase isoprene-OH reaction were significantly different from those observed in the corresponding gas phase reaction. The $\mathrm{Y}_{\mathrm{MG}}$, $\mathrm{Y}_{\mathrm{GL}}$, and $\mathrm{Y}_{\mathrm{OA}}$ varied with the reaction time. A box model was employed to simulate the reaction, focusing on the formation of multifunctional carbonyl compounds. Based on the experimental and model results, we suggested that the unexpected high $\mathrm{Y}_{\mathrm{MVK}} / \mathrm{Y}_{\mathrm{MACR}}$ ratio $(\sim 2)$ observed in the aqueous phase relative to that $(\sim 1)$ observed in the gas phase may arise from the water-induced acceleration of the peroxy radical $\mathrm{HOCH}_{2} \mathrm{C}\left(\mathrm{CH}_{3}\right)\left(\mathrm{O}_{2}\right) \mathrm{CH}=\mathrm{CH}_{2}$ self-reaction. Moreover, MG and GL may form through several pathways, including the oxidation of MACR/MVK (P1), the decomposition of subsequent products of $\mathrm{R}^{\mathrm{O}} \mathrm{O}_{2}$ and $\mathrm{R}^{2} \mathrm{O}_{2}$ peroxy radicals ( $\mathrm{P} 2)$, and the reaction between the hydroxy isoprene peroxyl radicals and the hydroxy MACR/MVK peroxyl radicals (P3). The $\mathrm{P} 2$ pathway may dominate in the production of MG and GL. In addition, HMW oxidation may also contribute to the production of MG and GL.

Using the aqueous rate constant determined in this work, we would like to evaluate the relative importance of aqueous surface $\mathrm{OH}$ oxidation of isoprene compared with the corresponding gas phase reaction. We assume that the gas phase isoprene molecules can collide with a droplet and react with the $\mathrm{OH}$ radicals on the aqueous phase surface. Herrmann et al. (2005) have estimated that the aqueous $\mathrm{OH}$ radicals come from the Fenton reaction between $\mathrm{Fe}^{2+}$ and $\mathrm{H}_{2} \mathrm{O}_{2}$ (account- ing for $33 \%$ ), the photolysis of $\mathrm{H}_{2} \mathrm{O}_{2}(25.5 \%)$, the uptake of gas phase $\mathrm{OH}$ radical $(21.6 \%)$, and the other sources $(20 \%)$. If the total surface aqueous phase reaction rate for all water droplets in unit volume of air and the gas phase reaction rate of isoprene- $\mathrm{OH}$ reaction are known, one can compare these two values to evaluate the relative importance of aqueous surface oxidation process in the atmosphere.

The surface aqueous phase reaction rate of two reactants depends on their aqueous-phase reaction rate constant and their surface concentrations on droplets. Up to date, there are no field measurement data about the aqueous surface concentrations of isoprene and $\mathrm{OH}$ radical. Since the amount of isoprene in the aqueous phase calculated from its Henry's law constant does not represent that on the surface of droplets based on the literatures mentioned in the introduction, this amount should be re-estimated with other parameters. Here, we try to provide reasonable values based on the available theory and literatures. The surface concentration of isoprene depends on its uptake rate by the surface of droplets. The surface uptake rate, $r_{\mathrm{s}}\left(\mathrm{mol} \mathrm{s}^{-1} \mathrm{~m}^{-3}\right.$ air), of isoprene by droplets can be given in Eq. (1) (Chen et al., 2008):

$r_{s}=\alpha_{\mathrm{s}} Z=\frac{1}{4} \alpha_{\mathrm{s}} \sqrt{\frac{8 R T}{\pi M_{\mathrm{x}}}} A_{\mathrm{s}}[\mathrm{ISO}]_{\mathrm{g}}$

Where $Z$ is the rate of isoprene collisions between the isoprene molecules and droplet surface, $\alpha_{\mathrm{S}}$ is the surface mass accommodation coefficient of isoprene, $\mathrm{A}_{\mathrm{s}}$ is the total effective surface area of droplets per unit volume of air, $R$ is the gas constant, $T$ is the temperature and $M_{\mathrm{x}}$ is the molecular weight of isoprene, [ISO $]_{\mathrm{g}}$ indicates the gas phase concentration of isoprene. One will expect the water content and the droplet size to play crucial roles in the droplet surface uptake rate in $1 \mathrm{~m}^{3}$ air. Here, we consider a cloud with liquid water content $1 \mathrm{~g}$ per $\mathrm{m}^{3}$ which form $0.2 \mu \mathrm{m}$ (possibly sub-micrometer-sized aqueous droplets) or $2 \mu \mathrm{m}$ droplets (cloud/fog) averagely, considering the major contribution of small droplets to the total droplet surface area in the cloud. Taking molecular dynamics simulation for $\alpha$-pinene uptake by aqueous water surface as a reference (Yu et al., 2008), we deduce that the residence time $t$ of isoprene on the surface is at least $10^{-9} \mathrm{~s}$ without desorption. Within this residence time, the surface mass accommodation coefficient of isoprene is assumed to be 1 . Additionally, up to now, there are no measured values of surface accommodation coefficients $\left(\alpha_{\mathrm{s}}\right)$, although bulk accommodation coefficients $\left(\alpha_{\mathrm{b}}\right)$ are available (Ervens et al., 2003). $\alpha_{\mathrm{s}}$ is the maximum value for $\alpha_{\mathrm{b}}$ (Pöschl et al., 2007), and the values of $\alpha_{\mathrm{s}}$ are likely to be very close to 1 for many atmospheric relevant conditions (M. Ammann at PSI, private communication, 2008). In this case, the Eq. (2) can be used to estimate the surface concentration $\{\mathrm{ISO}\}_{\mathrm{S}}$ of isoprene on droplets disregarding the desorption process, assuming that the surface concentration of 
Table 1. Several scenarios about the oxidation rates of isoprene by $\mathrm{OH}$ radical on the surface of droplets in $1 \mathrm{~m}^{3}$ air and a comparison with the corresponding gas phase reaction.

\begin{tabular}{|c|c|c|c|c|c|}
\hline & Scenario 1 & Scenario 2 & Scenario 3 & Scenario 4 & Scenario 5 \\
\hline$L_{\mathrm{W}}\left(\mathrm{g} \mathrm{m}^{-3}\right.$ air $)$ & 1.0 & 1.0 & 1.0 & 1.0 & 1.0 \\
\hline$D(\mathrm{~m})$ & $2.0 \times 10^{-7}$ & $2.0 \times 10^{-7}$ & $2.0 \times 10^{-6}$ & $2.0 \times 10^{-6}$ & $2.0 \times 10^{-6}$ \\
\hline$A_{\mathrm{s}}\left(\mathrm{m}^{2} \mathrm{~m}^{-3}\right.$ air $)$ & 30 & 30 & 3 & 3 & 3 \\
\hline$\alpha_{\mathrm{S}}$ & 1 & 1 & 1 & 1 & 1 \\
\hline$r_{\mathrm{S}}\left(\mathrm{mol} \mathrm{s}{ }^{-1} \mathrm{~m}^{-3}\right.$ air $)$ & $9.1 \times 10^{-5}$ & $9.1 \times 10^{-5}$ & $9.1 \times 10^{-6}$ & $9.1 \times 10^{-6}$ & $9.1 \times 10^{-6}$ \\
\hline$l(\mathrm{~m})$ & $1.0 \times 10^{-9}$ & $1.0 \times 10^{-9}$ & $1.0 \times 10^{-9}$ & $1.0 \times 10^{-9}$ & $1.0 \times 10^{-9}$ \\
\hline$t(\mathrm{~s})$ & $1.0 \times 10^{-8}$ & $1.0 \times 10^{-9}$ & $1.0 \times 10^{-9}$ & $1.0 \times 10^{-9}$ & $1.0 \times 10^{-9}$ \\
\hline$[\mathrm{ISO}]_{\mathrm{g}}(\mathrm{ppb})$ & 1.0 & 1.0 & 1.0 & 1.0 & 1.0 \\
\hline$\{\mathrm{ISO}\}_{\mathrm{V}}\left(\mathrm{mol} \mathrm{L}^{-1}\right)$ & $3.0 \times 10^{-8}$ & $3.0 \times 10^{-9}$ & $3.0 \times 10^{-9}$ & $3.0 \times 10^{-9}$ & $2.9 \times 10^{-11}$ \\
\hline$[\mathrm{OH}]_{\mathrm{g}}(\mathrm{ppt})$ & 0.3 & 0.3 & 0.3 & 0.3 & 0.3 \\
\hline$\{\mathrm{OH}\}_{\mathrm{V}}\left(\mathrm{mol} \mathrm{L}^{-1}\right)$ & $5.1 \times 10^{-10}$ & $5.1 \times 10^{-10}$ & $5.1 \times 10^{-10}$ & $5.1 \times 10^{-11}$ & $5.1 \times 10^{-11}$ \\
\hline$k_{\mathrm{gas}}\left(\mathrm{m}^{3} \mathrm{~mol}^{-1} \mathrm{~s}^{-1}\right)$ & $6.4 \times 10^{7}$ & $6.4 \times 10^{7}$ & $6.4 \times 10^{7}$ & $6.4 \times 10^{7}$ & $6.4 \times 10^{7}$ \\
\hline$k_{\mathrm{aq}}\left(L \mathrm{~mol}^{-1} \mathrm{~s}^{-1}\right)$ & $1.2 \times 10^{10}$ & $1.2 \times 10^{10}$ & $1.2 \times 10^{10}$ & $1.2 \times 10^{10}$ & $1.2 \times 10^{10}$ \\
\hline$R_{\text {gas }}\left(\mathrm{mol} \mathrm{s}^{-1} \mathrm{~m}^{-3}\right.$ air $)$ & $3.3 \times 10^{-11}$ & $3.3 \times 10^{-11}$ & $3.3 \times 10^{-11}$ & $3.3 \times 10^{-11}$ & $3.3 \times 10^{-11}$ \\
\hline$R_{\text {sur }}\left(\mathrm{mol} \mathrm{s}^{-1} \mathrm{~m}^{-3}\right.$ air $)$ & $5.5 \times 10^{-12}$ & $5.5 \times 10^{-13}$ & $5.5 \times 10^{-14}$ & $5.5 \times 10^{-15}$ & $1.3 \times 10^{-17}$ \\
\hline$R_{\text {sur }} / R_{\text {gas }}(\%)$ & 16 & 1.6 & 0.16 & 0.016 & $1.54 \times 10^{-4}$ \\
\hline
\end{tabular}

where $L_{\mathrm{W}}$ is the liquid water content in air; $D$ is the diameter of the droplet, $0.2 \mu \mathrm{m}$ and $2 \mu \mathrm{m}$ are considered here; $A_{\mathrm{S}}$ is the total surface area of droplets in $1 \mathrm{~m}{ }^{3}$ air; $\alpha_{\mathrm{S}}$ is the surface mass accommodation coefficient of isoprene, it is presumed to be $1 ; r_{\mathrm{s}}$ is the surface uptake rate of isoprene by the surface of droplets in $1 \mathrm{~m}^{3}$ air; $l$ is the thickness of the surface of droplets (Pöschl et al., 2007); $t$ is the residence time of isoprene on the surface of droplets, $1 \mathrm{~ns}$ and $10 \mathrm{~ns}$ are considered (Yu et al., 2008); [ISO]g is the gas phase concentration of isoprene; $\{\mathrm{ISO}\}_{v}$ is the aqueous surface concentration of isoprene; $[\mathrm{OH}]_{\mathrm{g}}$ is the gas phase concentration of $\mathrm{OH}$ radical; $\{\mathrm{OH}\}_{v}$ is the aqueous surface concentration of $\mathrm{OH}$ radical, $5.1 \times 10^{-10} \mathrm{M}$ and $5.1 \times 10^{-11} \mathrm{M}$ are considered, see the text; $k_{\text {gas }}$ is the reaction rate constant of isoprene with OH radical in the gas phase (Atkinson et al., 2006); $k_{\text {aq }}$ is the reaction rate constant of isoprene with $\mathrm{OH}$ radical in the aqueous phase (this work); $R_{\text {gas }}$ is the reaction rate of isoprene with oxidants in the gas phase; $R_{\text {sur }}$ is the reaction rate of isoprene with oxidants on the surface of droplets.

the reactant is initially zero:

$\{\mathrm{ISO}\}_{\mathrm{s}}=\frac{r_{\mathrm{s}} t}{A_{\mathrm{S}}}$

If both the surface concentrations of reactants and the surface reaction rate constants are available, then the aqueous phase reaction rates on the surface of droplets can be estimated. However, to the best of our knowledge, the surface reaction rate constants are not available. In order to use the available volume (bulk) aqueous phase reaction rate constant of isoprene-OH reaction, we should know the surface volume concentrations, $\{\mathrm{ISO}\}_{v}$, of isoprene in the surface layer of droplets. If $l$ is the thickness of the surface layer, then we can obtain:

$\{\mathrm{ISO}\}_{v}=\frac{\{\mathrm{ISO}\}_{\mathrm{S}}}{l}$

The thickness of the surface layer of droplets is assumed to be $1 \mathrm{~nm}$ (Pöschl et al., 2007). The concentration of surface $\mathrm{OH}$ radicals $\left(\{\mathrm{OH}\}_{v}\right)$ is another parameter that we need to know. For the gas phase mixing ratio $\left([\mathrm{OH}]_{\mathrm{g}}\right)$ of $\mathrm{OH}$ radicals with $0.3 \mathrm{pptv}$, the corresponding equilibrium concentration in the aqueous phase is $1.27 \times 10^{-11} \mathrm{M}$ (using a Henry's law constant of $39 \mathrm{M} \mathrm{atm}^{-1}$ at $283 \mathrm{~K}$, Sander, 1999). According to the ratio $(\sim 20 \%)$ of gas uptake to total aqueous $\mathrm{OH}$ radical (Herrmann et al., 2005), the aqueous bulk concentration is calculated as $6.4 \times 10^{-11} \mathrm{M}$. Vácha et al. (2004) have computationally simulated that the surface concentration of $\mathrm{OH}$ radicals is 8 times that in the bulk. Thus, we evaluate the surface concentration of $\mathrm{OH}$ radicals as $5.1 \times 10^{-10} \mathrm{M}$ when there is no other reaction loss, and estimate the surface steady state concentration as $5.1 \times 10^{-11} \mathrm{M}$. The reaction rate constant of isoprene with $\mathrm{OH}$ radical in the gas phase is $6.4 \times 10^{7} \mathrm{~m}^{3} \mathrm{~mol}^{-1} \mathrm{~s}^{-1}$ (Atkinson et al., 2006). Because there is no report about the rate constant on the aqueous surface for isoprene-OH reaction, here we use the rate constant determined in this work.

Then, the aqueous phase surface reaction rate $R_{\text {sur }}=k_{\text {sur }}$ $\{\mathrm{ISO}\}_{v}\{\mathrm{OH}\}_{v} \mathrm{~A}_{\mathrm{S}}$ in $1 \mathrm{~m}^{3}$ air, and the gas phase reaction rate $R_{\text {gas }}=k_{\text {gas }}[\mathrm{ISO}]_{\mathrm{g}}[\mathrm{OH}]_{\mathrm{g}}$ can be calculated. Thus, the ratio of $R_{\text {sur }} / R_{\text {gas }}$ can reflect the relative importance of aqueous surface process compared to the gas phase process. Here, we calculated the ratio of $R_{\text {sur }} / R_{\text {gas }}$ for several scenarios under different conditions, as shown in Table 1.

Five scenarios are provided in Table 1. There are three adjustable parameters, droplet diameter $(D)$, residence time $(t)$, and the concentration of $\mathrm{OH}$ radical on the aqueous surface $\left(\{\mathrm{OH}\}_{v}\right)$, the proposed values have been mentioned above. Scenario 1-4 considered the surface uptake of isoprene and the surface accommodation and the multiple sources of $\mathrm{OH}$ radical; Scenario 5 is the case that the surface concentrations of isoprene is equal to the bulk concentration $\left(2.9 \times 10^{-11} \mathrm{M}\right)$ calculated based on its Henry's law 
constant. We can see that Scenario 1 gives an upper limit for $R_{\text {sur }} / R_{\text {gas }}$ under our proposed conditions, that is, $D=0.2 \mu \mathrm{m}$, $t=10^{-8} \mathrm{~s}$, and $\{\mathrm{OH}\}_{v}=5.1 \times 10^{-10} \mathrm{M}$; scenario 4 gives a lower limit for $R_{\text {sur }} / R_{\text {gas }}$ when $D=2 \mu \mathrm{m}, t=10^{-9} \mathrm{~s}$, and $\{\mathrm{OH}\}_{v}=5.1 \times 10^{-11} \mathrm{M}$; scenario 2 and 3 describe the cases under the middle condition. However, there are still great uncertainties for the relative importance of aqueous surface $\mathrm{OH}$ oxidation for isoprene considering that there are no measured data for the actual $\mathrm{OH}$ concentration on the aqueous particles to verify the present predicted values, and the aqueous surface rate constant of isoprene-OH reaction is unknown. Noticeably, this work has provided experimental evidence for the effect of availably abundant water on the oxidation mechanism of atmospheric volatile organic compounds (VOCs). This reaction resulted in a different distribution of the oxygenated organic compounds compared to the corresponding gas phase reaction. We think the chemical pathways proposed in this study are possibly applicable to the surface reaction of the droplets or wet aerosols, and this may contribute to the aging of aerosols. We expect that our present study could add to the increasing body of literatures that cloud/fog/wet aerosol processing contributes to the SOA formation in the atmosphere. In addition, our present study is also related to the ocean isoprene SOA in the sea salt aerosol. Increasing evidence has indicated that the ocean emission is a source of isoprene in the ocean boundary layer (Milne et al., 1995; Shaw et al., 2003; Broadgate et al., 2004; Sinha et al., 2007), and field measurement has revealed the SOA existing in the sea aerosol (Cai and Griffin, 2003; Gantt et al., 2010; Miyazaki et al., 2010). The isoprene produced by the phytoplankton could react with $\mathrm{OH}$ radical in the sea water before entering into the atmosphere across the water-air interface, and this process would contribute to the sea salt aerosol components. It is well known that the sea salt aerosol arises from the spray of the sea surface water and its evaporation. One hand, this sea salt aerosol possibly contains isoprene SOA components produced in the sea water interface and bulk $\mathrm{OH}$-initiated oxidation of isoprene. Another hand, this aqueous phase reaction would result in an underestimation of isoprene emission by ocean.

\section{Supplementary material related to this article is available online at: http://www.atmos-chem-phys.net/11/7399/2011/ acp-11-7399-2011-supplement.pdf.}

Acknowledgements. The authors gratefully thank the National Natural Science Foundation of China (grants 21077003 and 40875072) and the State Key Laboratory of Environment Simulation and Pollution Control (special fund 10Z03ESPCP) for financial support.

Edited by: V. Faye McNeill

\section{References}

Aloisio, S. and Francisco, J. S.: Existence of a hydroperoxy and water $\left(\mathrm{HO}_{2} \cdot \mathrm{H}_{2} \mathrm{O}\right)$ radical complex, J. Phys. Chem. A., 102, 1899$1902,1998$.

Altieri, K. E., Seitzingera, S. P., Carlton, A. G., Turpin, B. J., Klein, G. C., and Marshall, A. G.: Oligomers formed through in-cloud methylglyoxal reactions: chemical composition, properties, and mechanisms investigated by ultra-high resolution FT-ICR mass spectrometry, Atmos. Environ., 42, 1476-1490, 2008.

Atkinson, R., Baulch, D. L., Cox, R. A., Crowley, J. N., Hampson, R. F., Hynes, R. G., Jenkin, M. E., Rossi, M. J., Troe, J., and IUPAC Subcommittee: Evaluated kinetic and photochemical data for atmospheric chemistry: Volume II - gas phase reactions of organic species, Atmos. Chem. Phys., 6, 3625-4055, doi:10.5194/acp-6-3625-2006, 2006.

Benkelberg, H. J., Böge, O., Seuwen, R., and Warneck, P.: Product distributions from the $\mathrm{OH}$ radical-induced oxidation of but1-ene, methyl-substituted but-1-enes and isoprene in $\mathrm{NO}_{\mathrm{X}}$-free air, Phys. Chem. Chem. Phys., 2, 4029-4039, 2000.

Böge, O., Miao, Y. K., Plewka, A., and Herrmann, H.: Formation of secondary organic particle phase compounds from isoprene gasphase oxidation products: an aerosol chamber and field study, Atmos. Environ., 40, 2501-2509, 2006.

Breslow, R.: Hydrophobic effects on simple organic reactions in water, Acc. Chem. Res., 24, 159-164, 1992.

Broadgate, W. J., Malin, G., Küpper, F. C., Thompson, A., and Liss, P. S.: Isoprene and other non-methane hydrocarbons from seaweeds: a source of reactive hydrocarbons to the atmosphere, Mar. Chem., 88, 61-73, 2004.

Butkovskaya, N. I., Kukui, A., Pouvesle, N., and Le Bras, G.: Formation of nitric acid in the gas-phase $\mathrm{HO}_{2}+\mathrm{NO}$ reaction: Effects of temperature and water vapor, J. Phys. Chem. A., 109, 65096520, 2005.

Buxton, G. V., Greenstock, C. L., Helman, W. P., and Ross, A. B.: Critical review of rate constants for the reactions of hydrated electrons, hydrogen atoms and hydroxyl radicals $\left(\mathrm{OH} / \mathrm{O}^{-}{ }^{-}\right)$in aqueous solution, J. Phys. Chem. Ref. Data., 17, 513-886, 1988.

Cai, X. Y. and Griffin, R. J.: Modeling the formation of secondary organic aerosol in coastal areas: Role of the sea-salt aerosol organic layer, J. Geophys. Res., 108, D15, doi:10.1029/2002JD003053, 2003.

Carlton, A. G., Turpin, B. J., Lim, H. J., Altieri, K. E., and Seitzinger, S.: Link between isoprene and secondary organic aerosol (SOA): Pyruvic acid oxidation yields low volatility organic acids in clouds, Geophys. Res. Lett., 33, L06822, doi:06810.01029/02005GL025374, 2006.

Carlton, A. G., Turpin, B. J., Altieri, K. E., Seitzinger, S., Reff, A., Lim, H. J., and Ervens, B.: Atmospheric oxalic acid and SOA production from glyoxal: results of aqueous photoxidation experiments, Atmos. Environ., 41, 7588-7602, 2007.

Chameides, W. L. and Davis, D. D.: The free radical chemistry of cloud droplets and its impact upon the composition of rain, J. Geophys. Res., 87, 4863-4877, 1982.

Chen, Z. M., Wang, H. L., Zhu, L. H., Wang, C. X., Jie, C. Y., and Hua, W.: Aqueous-phase ozonolysis of methacrolein and methyl vinyl ketone: a potentially important source of atmospheric aqueous oxidants, Atmos. Chem. Phys., 8, 2255-2265, doi:10.5194/acp-8-2255-2008, 2008.

Clark, J., English, A. M., Hansen, J. C., and Francisco, J. S.: Com- 
putational study on the existence of organic peroxy radical-water complexes $\left(\mathrm{RO}_{2} \cdot \mathrm{H}_{2} \mathrm{O}\right)$, J. Phys. Chem. A., 112, 1587-1595, 2008.

Clark, J., Call, S. T., Austin, D. E., and Hansen, J. C.: Computational study of isoprene hydroxyalkyl peroxy radical water complexes $\left(\mathrm{C}_{5} \mathrm{H}_{8}(\mathrm{OH}) \mathrm{O}_{2} \cdot \mathrm{H}_{2} \mathrm{O}\right)$, J. Phys. Chem. A., 114, 65346541, 2010.

Crahan, K. K., Hegg, D., Covert, D. S., and Jonsson, H.: An exploration of aqueous oxalic acid production in the coastal marine atmosphere, Atmos. Environ., 38, 3757-3764, 2004.

Edney, E. O., Kleindienst, T. E., Jaoui, M., Lewandowski, M., Offenberg, J. H., Wang, W., and Claeys, M.: Formation of 2-methyl tetrols and 2-methylglyceric acid in secondary organic aerosol from laboratory irradiated isoprene/ $\mathrm{NO}_{\mathrm{x}} / \mathrm{SO}_{2}$ /air mixtures and their detection in ambient PM2.5 samples collected in the eastern United States, Atmos. Environ., 39, 5281-5289, 2005.

El Haddad, I. E., Liu, Y., Nieto-Gligorovski, L., Michaud, V., Temime-Roussel, B., Quivet, E., Marchand, N., Sellegri, K., and Monod, A.: In-cloud processes of methacrolein under simulated conditions - Part 2: formation of secondary organic aerosol, Atmos. Chem. Phys., 9, 5107-5117, doi:10.5194/acp-9-5107-2009, 2009.

Enami, S., Hoffmann, M. R., and Colussi, A. J.: How phenol and $\alpha$-Tocopherol react with ambient ozone at gas/liquid interfaces, J. Phys. Chem. A., 113, 7002-7010, 2009.

Enami, S., Hoffmann, M. R., and Colussi, A. J.: Prompt formation of organic acids in pulse ozonation of terpenes on aqueous surfaces, J. Phys. Chem. Lett., 1, 2374-2379, 2010.

English, A. M., Hansen, J. C., Szente, J. J, and Maricq, M. M.: The effects of water vapor on the $\mathrm{CH}_{3} \mathrm{O}_{2}$ self-reaction and reaction with $\mathrm{HO}_{2}$, J. Phys. Chem. A., 112, 9220-9228, 2008.

Ervens, B., George, C., Williams, J. E., Buxton, G. V., Salmon, G. A., Bydder, M., Wilkinson, F., Dentener, F., Mirabel, P., Wolke, R., and Herrmann, H.: CAPRAM 2.4 (MODAC mechanism): An extended and condensed tropospheric aqueous phase mechanism and its application, J. Geophys. Res., 108, 4426, doi:10.1029/2002JD002202, 2003.

Finlayson-Pitts, B. J. and Pitts, J. N.: Chemistry of the Upper and Lower Atmosphere, Academic Press, New York, USA, 151-158, 2000.

Fu, T. M., Jacob, D. J., Wittrock, F., Burrows, J. P., Vrekoussis, M., and Henze, D. K.: Global budgets of atmospheric glyoxal and methylglyoxal, and implications for formation of secondary organic aerosols, J. Geophys. Res., 113, D15303, doi:10.1029/2007JD009505, 2008.

Gantt, B., Meskhidze, N, Zhang, Y., and Xu, J.: The effect of marine isoprene emissions on secondary organic aerosol and ozone formation in the coastal United States, Atmos. Environ., 44, 115$121,2010$.

Gäb, S., Turner, W. V., and Wolff, S.: Formation of alkyl and hydroxyalkyl hydroperoxides on ozonolysis in water and in air, Atmos. Environ., 29, 2401-2407, 1995.

Gill, P. S., Graedel, T. E., and Wechsler, C. J.: Organic films on atmospheric aerosol particles, fog droplets, cloud droplets, raindrops, and snowflakes, Rev. Geophys., 21, 903-920, 1983.

Gligorovski, S. and Herrmann, H.: Kinetics of reactions of $\mathrm{OH}$ with organic carbonyl compounds in aqueous solution, Phys. Chem. Chem. Phys., 6, 4118-4126, 2004.

Gligorovski, S., Rousse, D., George, C. H., and Herrmann, H.: Rate constants for the $\mathrm{OH}$ reactions with oxygenated organic compounds in aqueous solution, Intern, J. Chem. Kinet., 41, 309326, 2009.

Hallquist, M., Wenger, J. C., Baltensperger, U., Rudich, Y., Simpson, D., Claeys, M., Dommen, J., Donahue, N. M., George, C., Goldstein, A. H., Hamilton, J. F., Herrmann, H., Hoffmann, T., Iinuma, Y., Jang, M., Jenkin, M. E., Jimenez, J. L., Kiendler-Scharr, A., Maenhaut, W., McFiggans, G., Mentel, Th. F., Monod, A., Prvt, A. S. H., Seinfeld, J. H., Surratt, J. D., Szmigielski, R., and Wildt, J.: The formation, properties and impact of secondary organic aerosol: current and emerging issues, Atmos. Chem. Phys., 9, 5155-5236, doi:10.5194/acp-95155-2009, 2009.

Herrmann, H., Hoffmann, D., Schaefer, T., Bräuer P., and Tilgner, A.: Tropospheric aqueous-phase free-radical chemistry: radical sources, spectra, reaction kinetics and prediction tools, Chem. Phys. Chem., 11, 3796-3822, 2010.

Herrmann, H., Tilgner, A., Barzaghi, P., Majdik, Z., Gligorovski, S., Poulain, L., and Monod, A.: Towards a more detailed description of tropospheric aqueous phase organic chemistry: CAPRAM 3.0., Atmos. Environ., 39, 4351-4363, 2005.

Jacob, D. J.: Chemistry of $\mathrm{OH}$ in remote clouds and its role in the production of formic acid and peroxymonosulfate, J. Geophys. Res., 91, 9807-9826, 1986.

Jenkin, M. E. and Hayman, G. D.: Kinetics of reactions of primary, secondary and tertiary $\beta$-hydroxy peroxyl radicals, J. Chem. Soc. Faraday Trans., 91, 1911-1922, 1995.

Jenkin, M. E., Boyd, A. A., and Lesclaux, R.: Peroxy radical kinetics resulting from the $\mathrm{OH}$-initiated oxidation of 1,3-butadiene, 2,3-dimethyl-1,3-butadiene and isoprene, J. Atmos. Chem., 29, 267-298, 1998.

Kolb, C. E., Cox, R. A., Abbatt, J. P. D., Ammann, M., Davis, E. J., Donaldson, D. J., Garrett, B. C., George, C., Griffiths, P. T., Hanson, D. R., Kulmala, M., McFiggans, G., Pöschl, U., Riipinen, I., Rossi, M. J., Rudich, Y., Wagner, P. E., Winkler, P. M., Worsnop, D. R., and O'Dowd, C. D.: An overview of current issues in the uptake of atmospheric trace gases by aerosols and clouds, Atmos. Chem. Phys., 10, 10561-10605, doi:10.5194/acp-1010561-2010, 2010.

Kroll, J., Chan, A. W. H., Ng, N. L., Flagan, R. C., and Seinfeld,J. H.: Reactions of semivolatile organics and their effects on secondary organic aerosol formation, Environ. Sci. Technol., 41, 3545-3550, 2007.

Lee, W., Baasandorj, M., Stevens, P. S., and Hites, R. A.: Monitoring $\mathrm{OH}$-initiated oxidation kinetics of isoprene and its products using online mass spectrometry, Environ. Sci. Technol., 39, 1030-1036, 2005.

Legrand, M. and Puxbaum, H.: Summary of the CARBOSOL project: Present and retrospective state of organic versus inorganic aerosol over Europe, J. Geophys. Res., 112, D23S01, doi:10.1029/2006JD008271, 2007.

Lelieveld, J. and Crutzen, P. J.: The role of clouds in tropospheric photochemistry, J. Atmos. Chem., 12, 229-267, 1991.

Yao Liu, El Haddad, I., Scarfogliero, M., Nieto-Gligorovski, L., Temime-Roussel, B., Quivet, E., Marchand, N., PicquetVarrault, B., and Monod, A.: In-cloud processes of methacrolein under simulated conditions Part 1: Aqueous phase photooxidation, Atmos. Chem. Phys., 9, 5093-5105, doi:10.5194/acp-95093-2009, 2009. 
Michaud, V., El Haddad, I., Yao Liu, Sellegri, K., Laj, P., Villani, P., Picard, D., Marchand, N., and Monod, A.: In-cloud processes of methacrolein under simulated conditions - Part 3: Hygroscopic and volatility properties of the formed secondary organic aerosol, Atmos. Chem. Phys., 9, 5119-5130, doi:10.5194/acp-9-51192009, 2009.

Milne, P. J., Riemer, D. D., Zika, R. G., and Brand, L. E.: Measurement of vertical distribution of isoprene in surface seawater, its chemical fate, and its emission from several phytoplankton monocultures, Mar. Chem., 48, 237-244, 1995.

Miyazaki, Y., Kawamura, K., and Sawano, M.: Size distributions and chemical characterization of water-soluble organic aerosols over the western North Pacific in summer, J. Geophys. Res., 115, D23210, doi:10.1029/2010JD014439, 2010.

Miyoshi, A., Hatakeyama, S., and Washida, N.: OH radicalinitiated photo-oxidation of isoprene: an estimate of global CO production, J. Geophys. Res., 99, 8779-18787, 1994.

Mmereki, B. T. and Donaldson, D. J.: Laser induced fluorescence of pyrene at an organic coated air-water interface, Phys. Chem. Chem. Phys., 4, 4186-4191, 2002.

Monod, A., Chebbi, A., Durand-Jolibois, R., and Carlier, P.: Oxidation of methanol by hydroxyl radicals in aqueous solution under simulated cloud droplet conditions, Atmos. Environ., 34, 52835294, 2000.

Monod, A., Poulain, L., Grubert, S., Voisin, D., and Wortham, H.: Kinetics of $\mathrm{OH}$-initiated oxidation of oxygenated organic compounds in the aqueous phase: new rate constants, structureactivity relationships and atmospheric implications, Atmos. Environ., 39, 7667-7688, 2005.

Na, K., Song, C., and Cocker III, D. R.: Formation of secondary organic aerosol from the reaction of styrene with ozone in the presence and absence of ammonia and water, Atmos. Environ., 40, 1889-1900, 2006.

Neeb, P., Sauer, F., Horie, O., and Moortgat, G. K.: Formation of hydroxymethyl hydroperoxide and formic acid in alkene ozonolysis in the presence of water vapour, Atmos. Environ., 31, 14171423, 1997.

Neta, P., Huie, R. E., and Ross, A. B.: Rate constants for reactions of peroxyl radicals in fluid solutions, J. Phys. Chem. Ref. Data., 19, 413-513, 1990.

Ng, N. L., Kroll, J. H., Chan, A. W. H., Chhabra, P. S., Flagan, R. C., and Seinfeld, J. H.: Secondary organic aerosol formation from m-xylene, toluene, and benzene, Atmos. Chem. Phys., 7, 39093922, doi:10.5194/acp-7-3909-2007, 2007.

Perri, M. J., Seitzinger, S. P., and Turpin, B. J.: Secondary organic aerosol production from aqueous photooxidation of glycolaldehyde: laboratory experiments, Atmos. Environ., 43, 1487-1497, 2009.

Pöschl, U., Rudich, Y., and Ammann, M.: Kinetic model framework for aerosol and cloud surface chemistry and gas-particle interactions - Part 1: General equations, parameters, and terminology, Atmos. Chem. Phys., 7, 5989-6023, doi:10.5194/acp-75989-2007, 2007.

Reichert, L., Andrés Hernández, M. D., Stöbener, D., Burkert, J., and Burrows, J. P.: Investigation of the effect of water complexes in the determination of peroxy radical ambient concentrations: Implications for the atmosphere, J. Geophys. Res. Atmos., 108, 4017, doi:10.1029/2002JD002152, 2003.

Ruppert, L. and Becker, K. H.: A product study of the $\mathrm{OH}$ radi- calinitiated oxidation of isoprene: formation of C5-unsaturated diols, Atmos. Environ., 34, 1529-1542, 2000.

Sander, R.: Compilation of Henry's law constants for inorganic and organic species of potential importance in environmental chemistry, Version 3, http://www.mpch-mainz.mpg.de/Bsander/ res/henry.html, 1999.

Sauer, F., Schafer, C., Neeb, P., Horie, O., and Moortgat, G. K.: Formation of hydrogen peroxide in the ozonolysis of isoprene and simple alkenes under humid conditions, Atmos. Environ., 33, 229-241, 1999.

Schwier, A. N., Sareen, N., Mitroo, D., Shapiro, E. L., and McNeill, V. F.: Glyoxal-methylglyoxal cross-reactions in secondary organic aerosol formation, Environ. Sci. Technol., 44, 6174-6182, 2010.

Seinfeld, J. H. and Pandis, S. N.: From Air Pollution to Climate Change, Atmospheric Chemistry and Physics, second edition, Wiley, New York, p. 290, 2006.

Shaw, S. L., Chisholm, S. W., and Prinn, R. G.: Isoprene production by Prochlorococcus, a marine cyanobacterium, and other phytoplankton, Mar. Chem., 80, 227-245, 2003.

Sinha, V., Williams, J., Meyerhfer, M., Riebesell, U., Paulino, A. I., and Larsen, A.: Air-sea fluxes of methanol, acetone, acetaldehyde, isoprene and DMS from a Norwegian fjord following a phytoplankton bloom in a mesocosm experiment, Atmos. Chem. Phys., 7, 739-755, doi:10.5194/acp-7-739-2007, 2007.

Suma, K., Sumiyoshi, Y., and Endo, Y.: The rotational spectrum of the water-hydroperoxy radical $\left(\mathrm{H}_{2} \mathrm{O} \cdot \mathrm{HO}_{2}\right)$ complex, Science, 311, 1278-1281, doi:10.1126/science.1124022, 2006.

Tan, Y., Perri, M. J., Seitzinger, S. P., and Tuipin, B. J.: Effects of precursor concentration and acidic sulfate in aqueous glyoxal$\mathrm{OH}$ radical oxidation and implications for secondary organic aerosol, Environ. Sci. Technol., 43, 8105-8112, 2009.

Tan, Y., Carlton, A. G., Seitzingera, S. P., and Turpin, B. J.: SOA from methylglyoxal in clouds and wet aerosols: measurement and prediction of key products, Atmos. Environ., 44, 5218-5226, 2010.

Taraborrelli, D., Lawrence, M. G., Butler, T. M., Sander, R., and Lelieveld, J.: Mainz Isoprene Mechanism 2 (MIM2): an isoprene oxidation mechanism for regional and global atmospheric modelling, Atmos. Chem. Phys., 9, 2751-2777, doi:10.5194/acp-92751-2009, 2009.

Vácha, R., Slavíèek, P., Mucha, Finlayson-Pitts, B. J., and Jungwirth, P.: Adsorption of Atmospherically Relevant Gases at the Air/Water Interface: Free Energy Profiles of Aqueous Solvation of $\mathrm{N}_{2}, \mathrm{O}_{2}, \mathrm{O}_{3}, \mathrm{OH}, \mathrm{H}_{2} \mathrm{O}, \mathrm{HO}_{2}$, and $\mathrm{H}_{2} \mathrm{O}_{2}$, J. Phys. Chem. A., 108, 11573-11579, 2004.

Volkamer, R., Martini, F. S., Molina, L. T., Salcedo, D., Jimenez, J. L., and Molina, M. J.: A missing sink for gas-phase glyoxal in Mexico City: Formation of secondary organic aerosol, Geophys. Res. Lett., 34, L19807, doi:10.1029/2007GL030752, 2007.

Walcek, C. J., Yuan, H. H., and Stockwell, W. R.: The influence of aqueous-phase chemical reaction on ozone formation in polluted and nonpolluted clouds, Atmos. Environ., 31, 1221-1237, 1997.

Wang, H. L., Zhang, X., and Chen, Z. M.: Development of DNPH/HPLC method for the measurement of carbonyl compounds in the aqueous phase: applications to laboratory simulation and field measurement, Environ. Chem., 6, 389-397, 2009.

Wang, H. L., Huang, D., Zhang, X., Zhao, Y., and Chen, Z. M.: The ozonolysis of isoprene in water forms peroxides and carbonyl 
compounds, in preparation, 2011.

Warneck, P.: In-cloud chemistry opens pathway to the formation of oxalic acid in the marine atmosphere, Atmos. Environ., 37, 2423-2427, 2003.

Warren, B., Malloy, Q. G. J., Yee, L. D., and Cocker, D. R.: Secondary organic aerosol formation from cyclohexene ozonolysis in the presence of water vapor and dissolved salts, Atmos. Environ., 43, 1789-1795, 2009.

Yu, L. E., Shulman, M. L., Kopperud, R., and Hildemann, L. M.: Characterization of organic compounds collected during the southeastern aerosol and visibility study: Water-soluble organic compounds, Environ. Sci. Technol., 39, 707-715, 2005.

Yu, Y., Ezell, M. J., Zelenyuk, A., Imre, D., Alexander, L., Ortega, J., Thomas, J. L., Gogna, K., Tobias, D. J., D’Anna, B., Harmon, C. W., Johnson, S. N., and Finlayson-Pitts, B. J.: Nitrate ion photochemistry at interfaces: a new mechanism for oxidation of a-pinene, Phys. Chem. Chem. Phys., 10, 3063-3071, 2008.
Zhang, X., Chen, Z. M., Wang, H. L., He, S. Z., and Huang, D. M.: An important pathway for ozonolysis of alpha-pinene and betapinene in aqueous phase and its implications, Atmos. Environ., 43, 4465-4471, 2009.

Zhang, X., Chen, Z. M., and Zhao, Y.: Laboratory simulation for the aqueous $\mathrm{OH}$-oxidation of methyl vinyl ketone and methacrolein: Significance to the in-cloud SOA production, Atmos. Chem. Phys., 10, 9551-9561, doi:10.5194/acp-10-9551-2010, 2010.

Zhao, J., Zhang, R., Fortner, E. C., and North, S. W.: Quantification of hydroxycarbonyls from OH-isoprene reactions, J. Am. Chem. Soc., 126, 2686-2687, 2004.

Zimmermann, J. and Poppe, D.: a supplement for the RADM2 chemical mechanism: the photooxidation of isoprene, Atmos. Environ., 8, 30, 1255-1269, 1996. 